Original Research Paper

\title{
Technical Stability of Very Slender Rectangular Columns Compressed by Ball-And-Socket Joints without Friction
}

\author{
Krzysztof Murawski \\ Independent Researcher, Poland
}

Article history

Received: 31-08-2020

Revised: 07-10-2020

Accepted: 24-10-2020

Email: k.murawski@interia.pl

\begin{abstract}
Stability of load-bearing members, as known, is a challenging issue and several tools are available for designers. Disregarding the material properties in use, the avoidance of possible stability troubles is a mandatory and challenging step of the overall design process. In this study, a theoretical model is presented for the of loss of stability in elastic states of very slender rectangular shell elements axially compressed through balland-socket joints without friction. According to this theory, as shown, a loss of carrying capacity of very slender columns in elastic states occurs when the line of force leaves a critical transverse cross-section. The critical transverse cross-section, moreover, progressively moves because of the superposition of bending and pure compression. The theory allows to determine the governing differential equations of curved central lines and their slopes, as well as the critical stresses of columns, in the form of surface function in dependence on slenderness ratios and cross-sectional areas. The graphs for the elastic deflected central line $y(x)$, slope $d y / d x$, dependence $y_{L / 2}(P)$, stresses and strains for a rectangular column made of steel and compressed by ball-and-socket joints without friction, as well as the corresponding surface graphs of critical stress, are presented in this study. The obtained surface graphs of critical stresses are then discussed and compared with Euler's formulation.
\end{abstract}

Keywords: Stability, Elastic States, Slenderness, Rectangular Columns, Steel

\section{Introduction}

Shell structures, in the field of building construction and engineering in general, represent a thin, curved plate structure that is optimally shaped to transmit applied forces by compressive, tensile and shear stresses that act in the plane of the same surface. When we consider the application of shell elements in load-bearing structures, accordingly, the first issue to analyze is their load capacity to sustain axial loads, i.e., their stability and susceptibility to potential buckling collapse mechanisms that could compromise the structure and occupant safety. In the case of very slender columns, this refers to the problem of stability in elastic states.

The basic theory of slender rods losing stability in elastic states, as known, has been originally formulated by (Euler, 1744; 1759). He first introduced the concept of critical load $P_{c r}$ and presented, according to his theory, the differential equation of an elastic deflected central line, that is:

$$
E J \frac{d^{2} y}{d x^{2}}=-P_{c r} y
$$

Where:

$E$ : Denotes the Young's modulus of elasticity of the column

$J$ : The moment of inertia of the cross-section area, while

$y$ : Represents the distance from the undeformed central line, from the $y$-axis

He had assumed a displacement $y(x)$ of the column axis as a part of a sine curve:

$$
y(x)=\sin \left(n \cdot \frac{\pi}{L} x\right),
$$

Where:

$n$ : Denotes the coefficient of the sine curve part and depends on boundaries ( $n=1$ for a pinned column, $n$ 
$=2$ for a column fixed at one end, $n=1 / 2$ for a column fixed by a pinned end and a vertically slide for the second end, $n=0.7$ for a column with a pinned end and a pinned vertical slide at the second end)

$L$ : The length of the bar

And he has obtained the formula for a critical stress $\sigma_{c r}$ of an axially compressed column by force as follows:

$$
\sigma_{c r}^{\text {Euler }}=\left(\frac{\pi}{n \cdot \lambda}\right)^{2} E .
$$

The problem of the stability was later searched and analyzed further with a focus on many other relevant aspects for various engineering applications, like buckling of columns composed of various constructional materials (Gupta et al., 2001; Oleiwi et al., 2014; Schnabl et al., 2013; Kalamar et al., 2016; Wahrhaftig et al., 2016; Thermou et al., 2018; Zhou et al., 2017; Ye et al., 2018; Osmani and Meftah, 2018; Wang et al., 2018; Naderpour et al., 2019; Qi et al., 2019; Goroshko et al., 2020), as well as beams (Ascione and Grimaldi, 1983; Di Sarno and Manfredi, 2012; Li et al., 2015; Özbaşaran et al., 2015; Monsalve-Cano and Aristizábal-Ochoa, 2016; Nguyen et al., 2018; Belaid et al., 2018) or nanobeams (Rahmani et al., 2017; Mohammadi et al., 2019).

Single-layer graphene sheets have been examined in (Genoese et al., 2019), while polymer-confined concrete columns have been discussed in (Liang et al., 2012) and hyperelastic tubes are analyzed by (Liu,
2018). Many other research contributions have been then related to the stability issues of a multitude of loadbearing systems and members can be found in the literature, including plates (Sabouri-Ghomi et al., 2008; Rao and Ra, 2009; Xu et al., 2013; Moradi-Dastjerdi and Malek-Mohammadi, 2017; Riahi et al., 2018; Vu et al., 2019) and nanoplates (Malikan et al., 2018), bracing systems (Rahnavard et al., 2018), tubes (Nouri et al., 2015; Mozafari et al., 2018; Naveed et al., 2017; Sadath et al., 2017; Sun et al., 2018), frames (Marante et al., 2012; Slimani et al., 2018), pipes (Lolov and Lilkova-Markova, 2005; Melissianos et al., 2017; Moustabchir et al., 2018; Psyrras et al., 2019), or Functionally Graded Material (FGM) structures (Moita et al., 2018; Kiss, 2019; Singh and Harsha, 2019), etc.

\section{Stability Analysis}

This research study herein discussed assumes as its own method of analysis for the column stability in elastic states that the state of stresses and strains in a critical transverse section (after losing stability and before losing its carrying capacity) appears as a superposition result of pure compression phenomena and bending effects (Fig. 1 and also (Murawski and Kłos, 2007; Murawski, 1992; 2011; 2018)). The method is thus developed on a basic simplification for very slender columns, that is the beginning of the load-carrying capacity lost (i.e., the maximum achieved value of force, on a force $P$-shortening $\Delta L$ graph) in elastic states follows the exceedance of the force line from a critical transverse section.

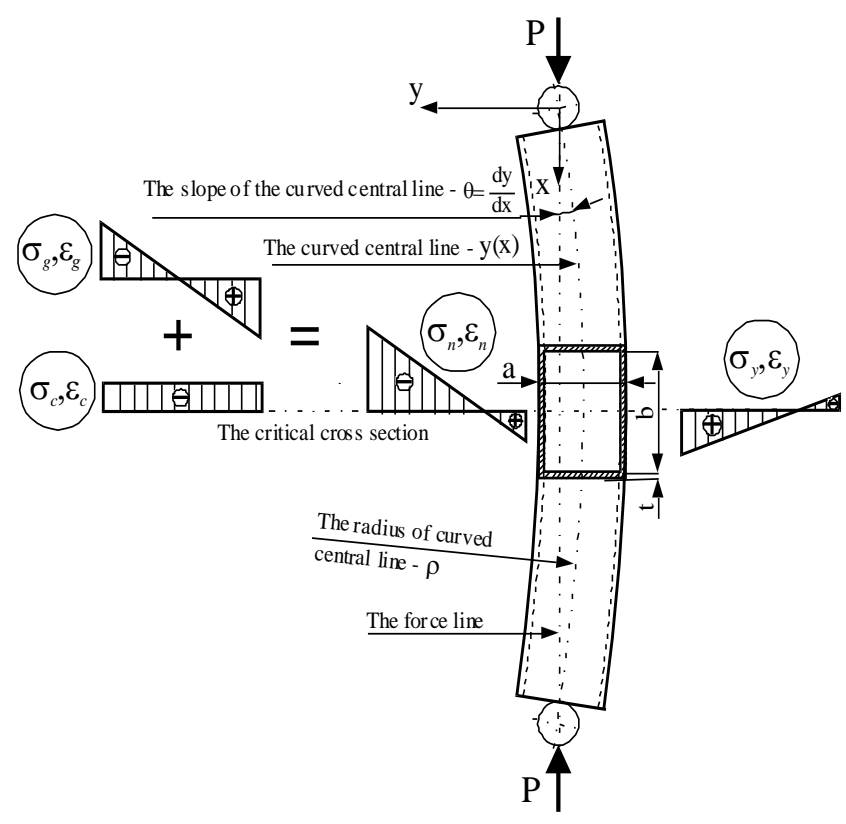

Fig. 1: Stress and strain analysis in the critical transverse section for a rectangular column axially compressed by force through balland- socket joints, after the loss of stability and before the loss of carrying capacity 
The fibre extension $\varepsilon$ at the distance $y$ from the undeformed central line and the corresponding stress $\sigma_{n}$ are in fact given by (Fig. 1):

$$
\begin{aligned}
& \varepsilon=\frac{ \pm(\rho+y) \cdot \theta-\rho \cdot \theta}{\rho \cdot \theta}= \pm \frac{y}{\rho}, \\
& \sigma_{n}=\sigma_{g}-\sigma_{c}= \pm \frac{y}{\rho} \cdot E-\frac{P}{A},
\end{aligned}
$$

where, $E$ is defined in Equation (1), while:

$\rho$ : Denotes the radius of the curved central line

$\theta$. The angle of the central line slope, in relation to the force line

$P$ : The imposed axial force

$A$ : The area of the critical cross-section

$\sigma_{g}:$ Represents the bending stress

$\sigma_{c}$ : The compressive stress

$\sigma_{n}$ : The normal stress

Due to the force equilibrium, it is:

$$
d P=\left(\sigma_{g}+\sigma_{c}\right) \cdot d A=\left( \pm \frac{y}{\rho} \cdot E-\frac{P}{A}\right) \cdot d A
$$

In this study, unlike Euler, it is moreover assumed that the displacement of the column axis is determined by taking into account the conditions of the small deformation theory, as a function of the curvature radius, that is:

$\frac{1}{\rho} \cong \frac{d^{2} y}{d x^{2}}$,

and the reference boundary conditions:

$d y / d x=0$ when $x=L / 2$, and:

$y=0$ when $x=0$,

The governing differential equations for the curved central line $d^{2} y / d x^{2}$ and its slope $d y / d x$, as well as the equation of the central line $y(x)$ for a column axially compressed by force through ball-and-socket joints without friction are like Equation (59), (60), (61) in (Murawski, 2011), or Equation (2.7), (2.8), (2.9) in (Murawski, 2018). From the assumption that the losing of carrying capacity follows when the force line exceeds the critical transverse section $\left(y_{x}=L / 2=y_{c r}\right)$, moreover, the critical stress $\sigma_{c r}$ for axially compressed columns under force through ball-and-socket joints is like Equation (65) in (Murawski, 2011), or Equation (2.13) in (Murawski, 2018).

\section{Theoretical Example}

As a theoretical example, the graphs of the elastic line $y(x)$, its slope $d y / d x$ and the dependence $y_{L / 2}(P)$ for a rectangular column made of steel are presented. In doing so, a steel column agreeing with Fig. 1 is taken into account.

Moreover, the nominal dimensions of the examined column are set in $a=20 \mathrm{~mm}, b=28 \mathrm{~mm}$ and $t=1 \mathrm{~mm}$ for the resisting cross-section, while $L=$ $2500 \mathrm{~mm}$ is the selected span (and $\lambda=314.8$ the corresponding slenderness) and the column is compressed by ball-and-socket joints. The socollected results are presented in Fig. 2.

Under the assumption that the loss of carrying capacity occurs when the force line leaves the critical transverse section $\left(y_{x=L / 2}=y_{c r}=a / 2+t\right)$, the dependency of various geometrical parameters on the mechanical performance of the selected column is highlighted in Figs. 3a-3d.

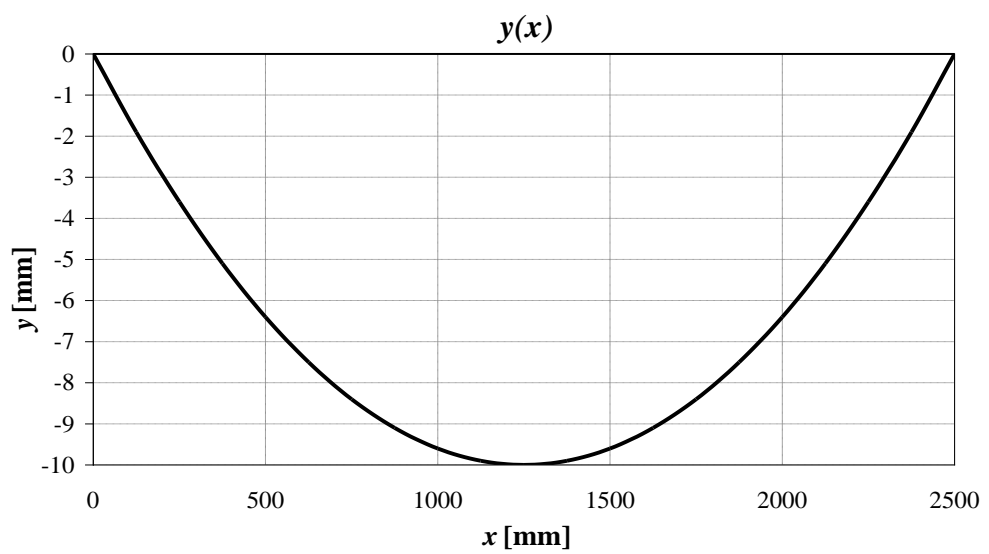

(a) 
Krzysztof Murawski / International Journal of Structural Glass and Advanced Materials Research 2020, Volume 4: 186.208 DOI: 10.3844/sgamrsp.2020.186.208

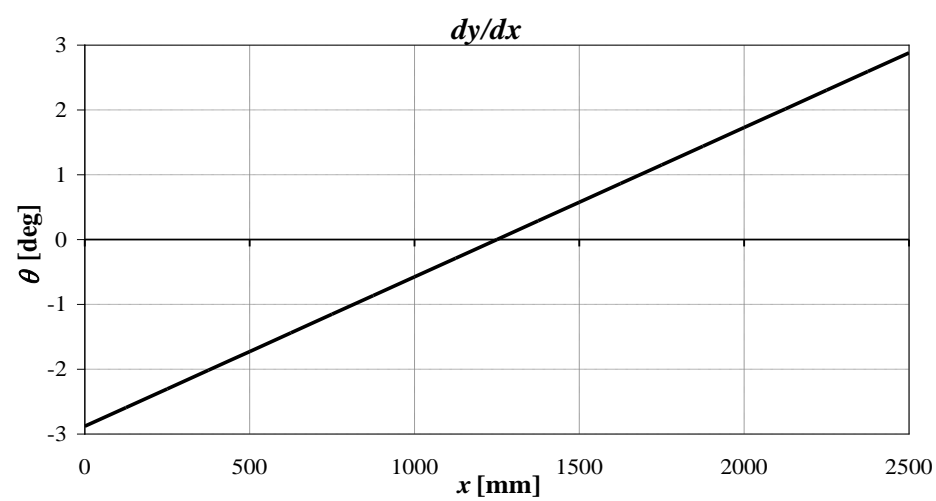

(b)

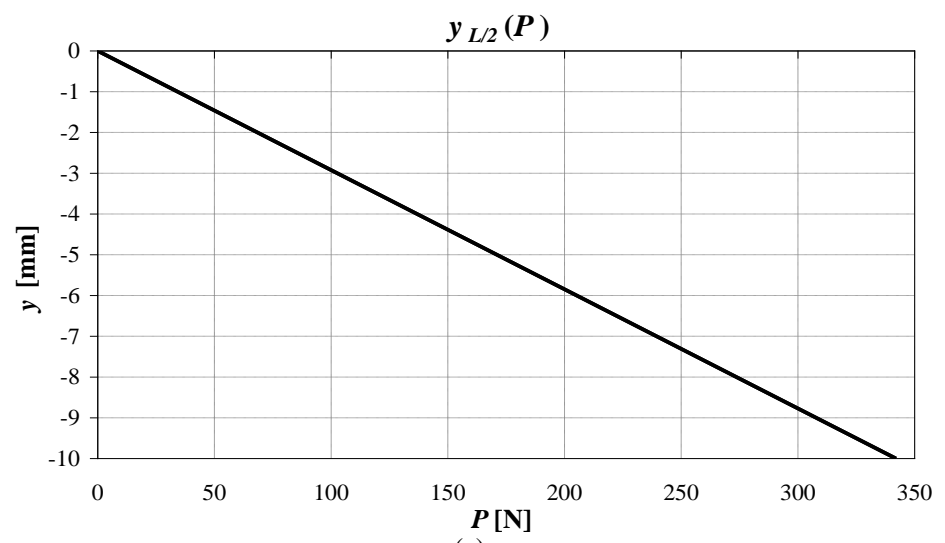

(c)

Fig. 2: Evolution of (a) elastic line $y(x)$, (b) elastic line slope $d y / d x$ and (c) function $y_{L}(P)$ for a rectangular steel column (dimensions: $a=20 \mathrm{~mm}, b=28 \mathrm{~mm}, t=1 \mathrm{~mm}, L=2500 \mathrm{~mm}$ ) compressed by ball-and-socket joints

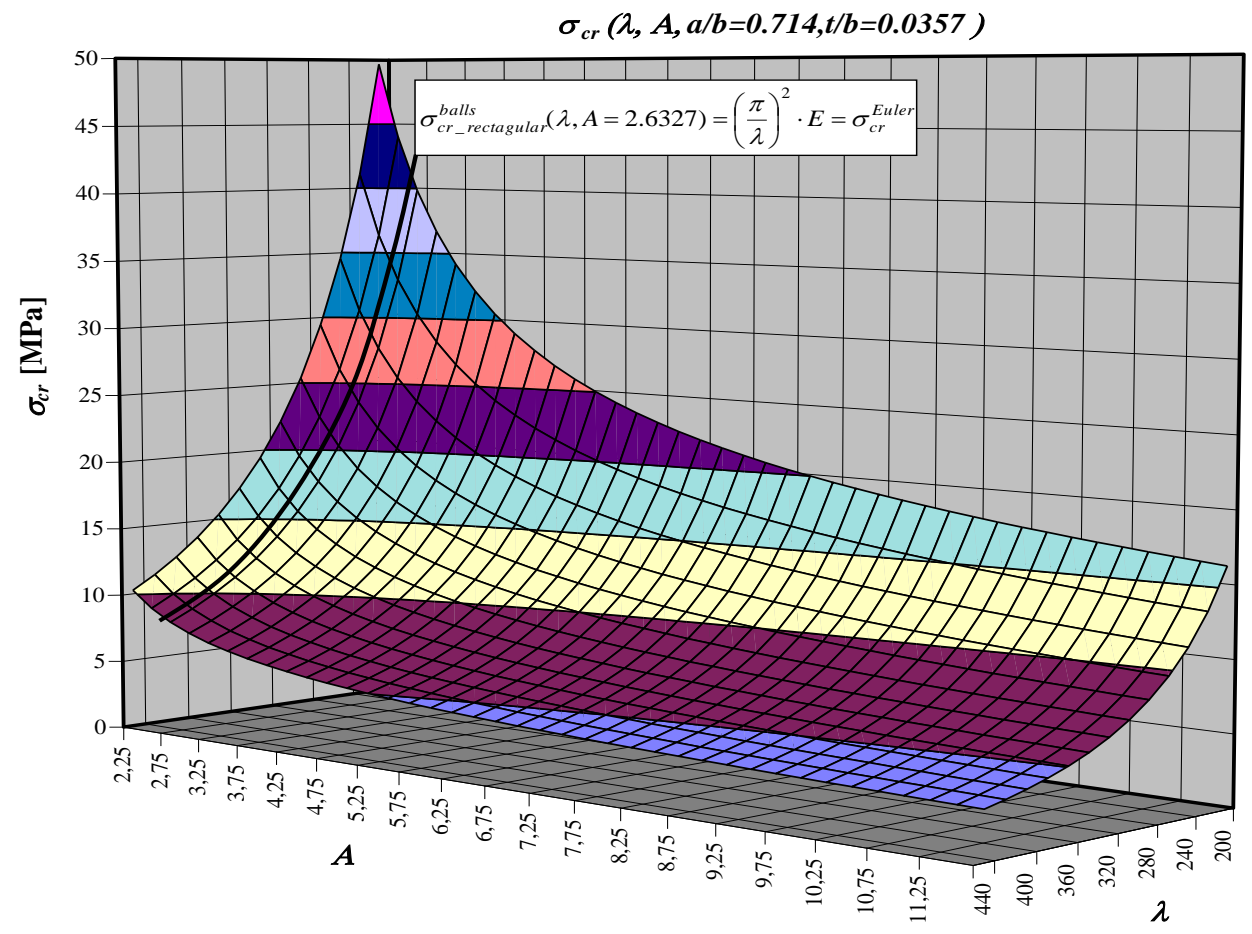

(a) 
Krzysztof Murawski / International Journal of Structural Glass and Advanced Materials Research 2020, Volume 4: 186.208 DOI: $10.3844 /$ sgamrsp.2020.186.208

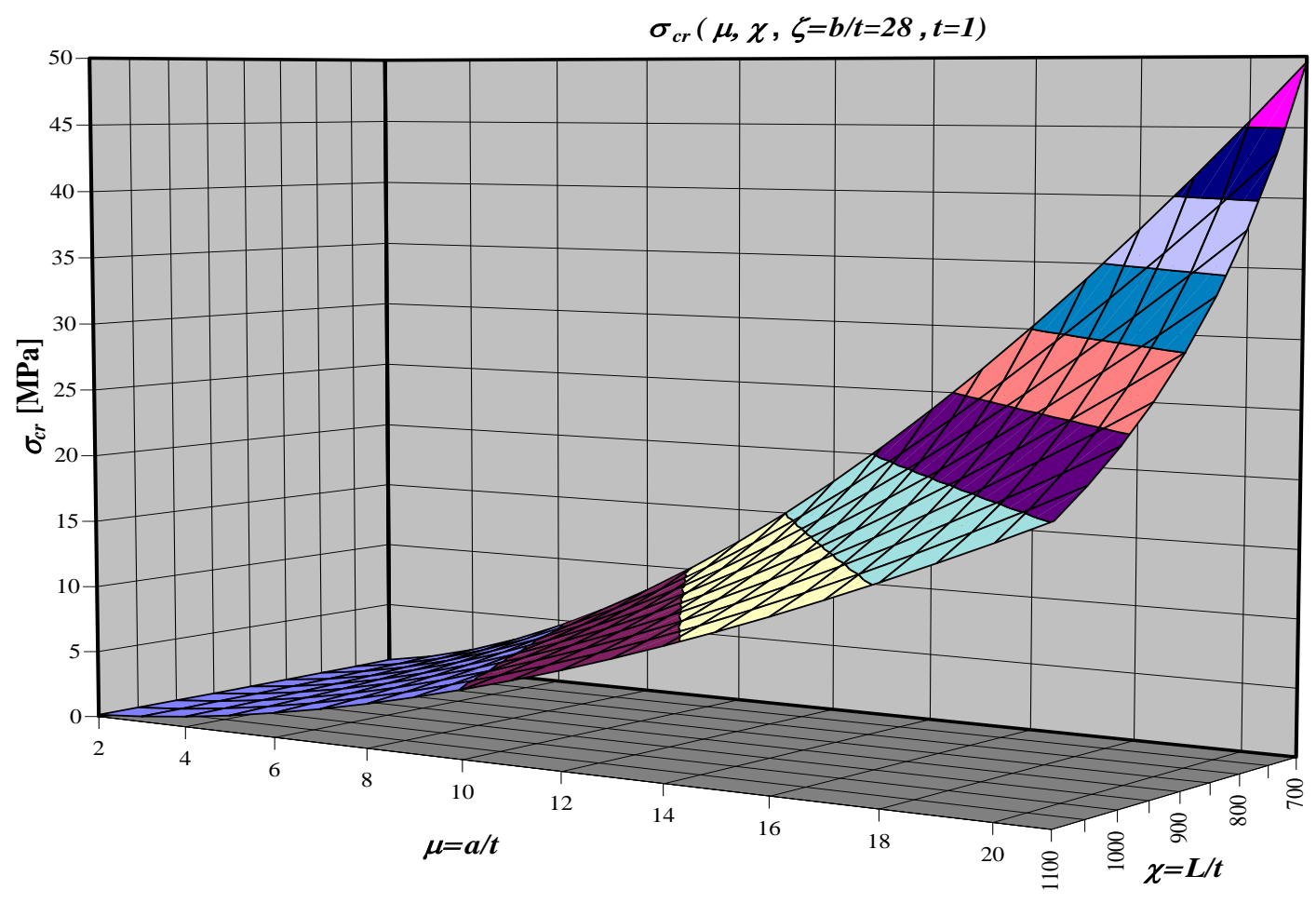

(b)

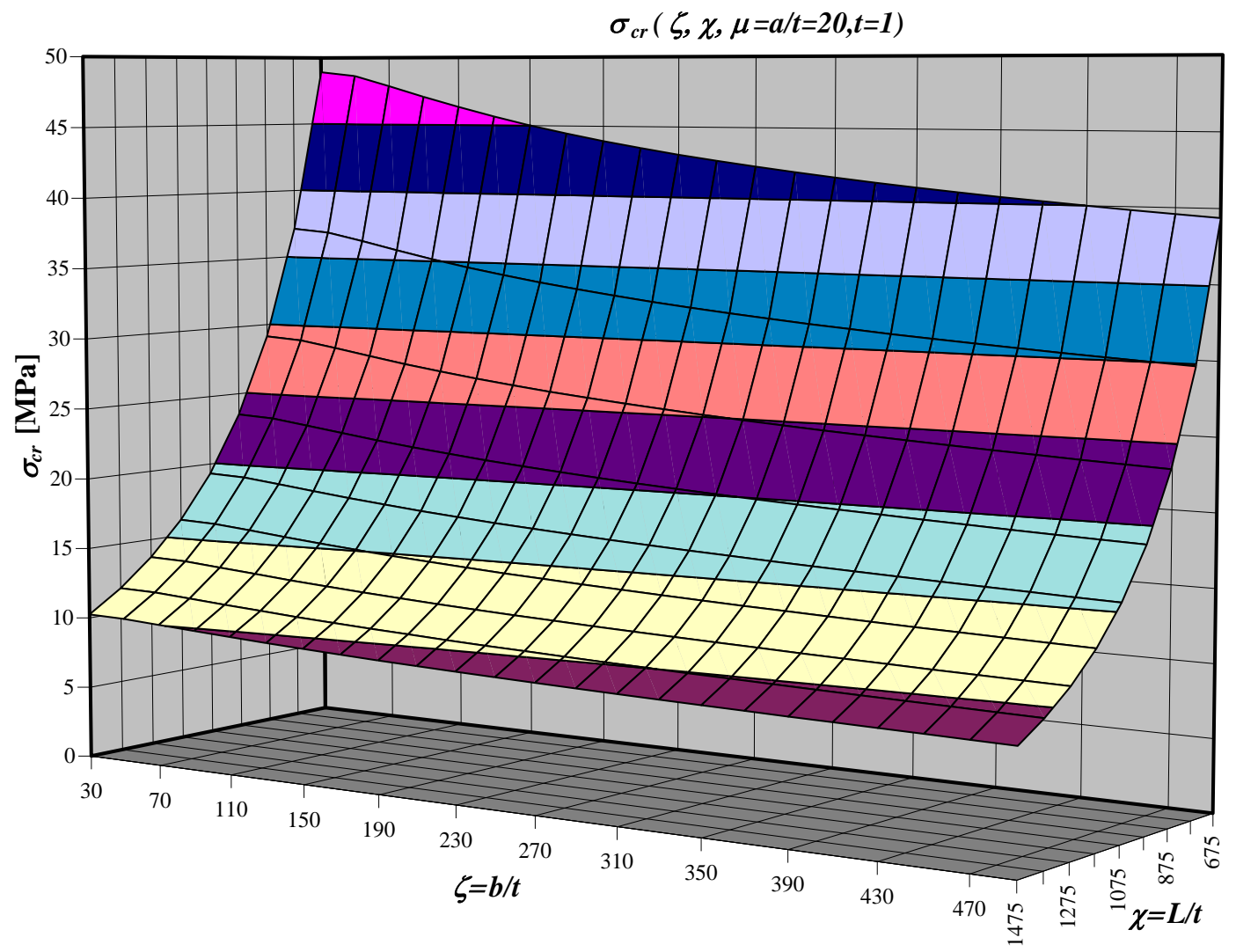

(c) 
Krzysztof Murawski / International Journal of Structural Glass and Advanced Materials Research 2020, Volume 4: 186.208 DOI: $10.3844 /$ sgamrsp.2020.186.208

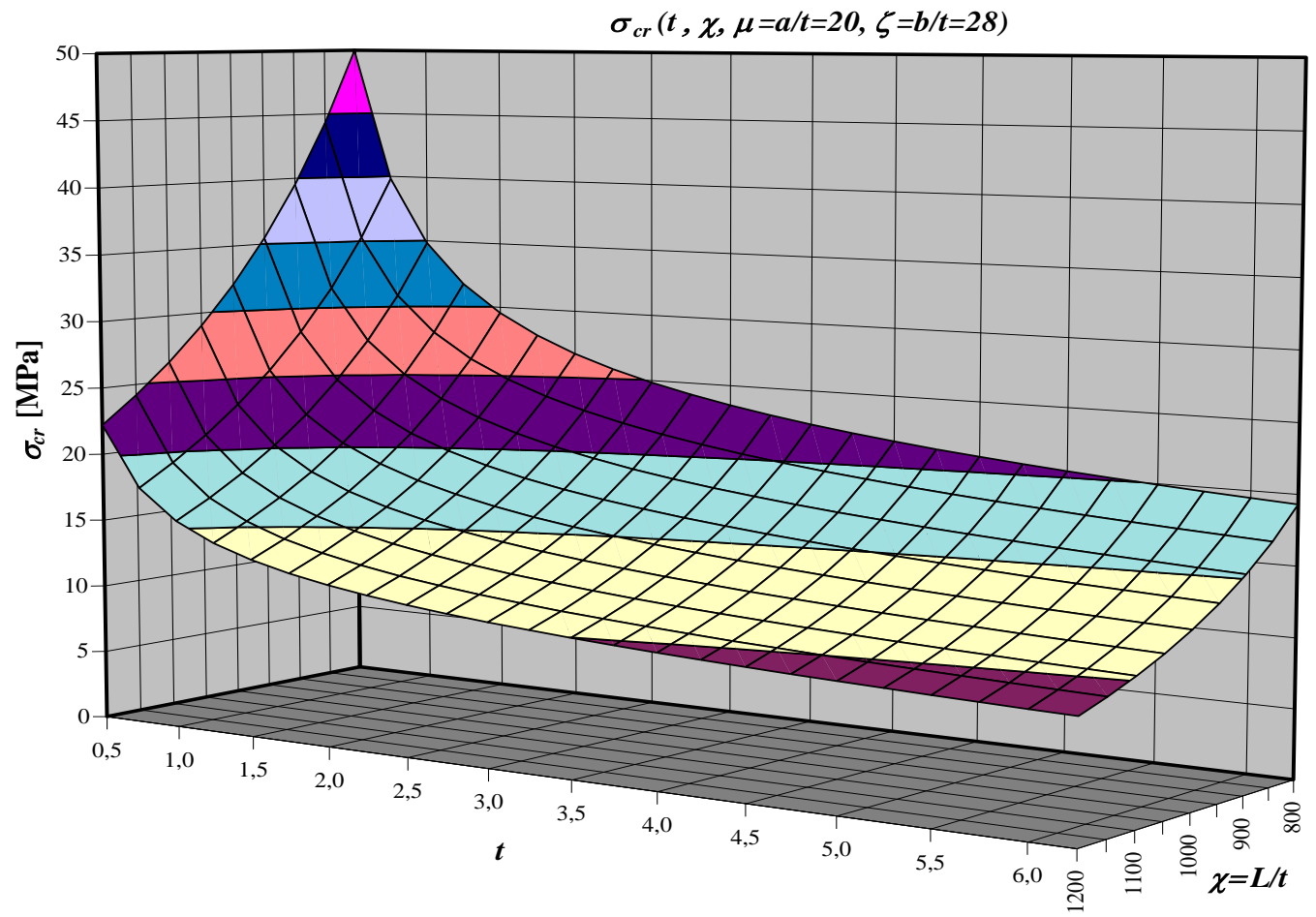

(d)

Fig. 3: Surface functions of critical stress for rectangular shaped shells made of steel and axially compressed by force through balland-socket joints, according to the technical stability theory

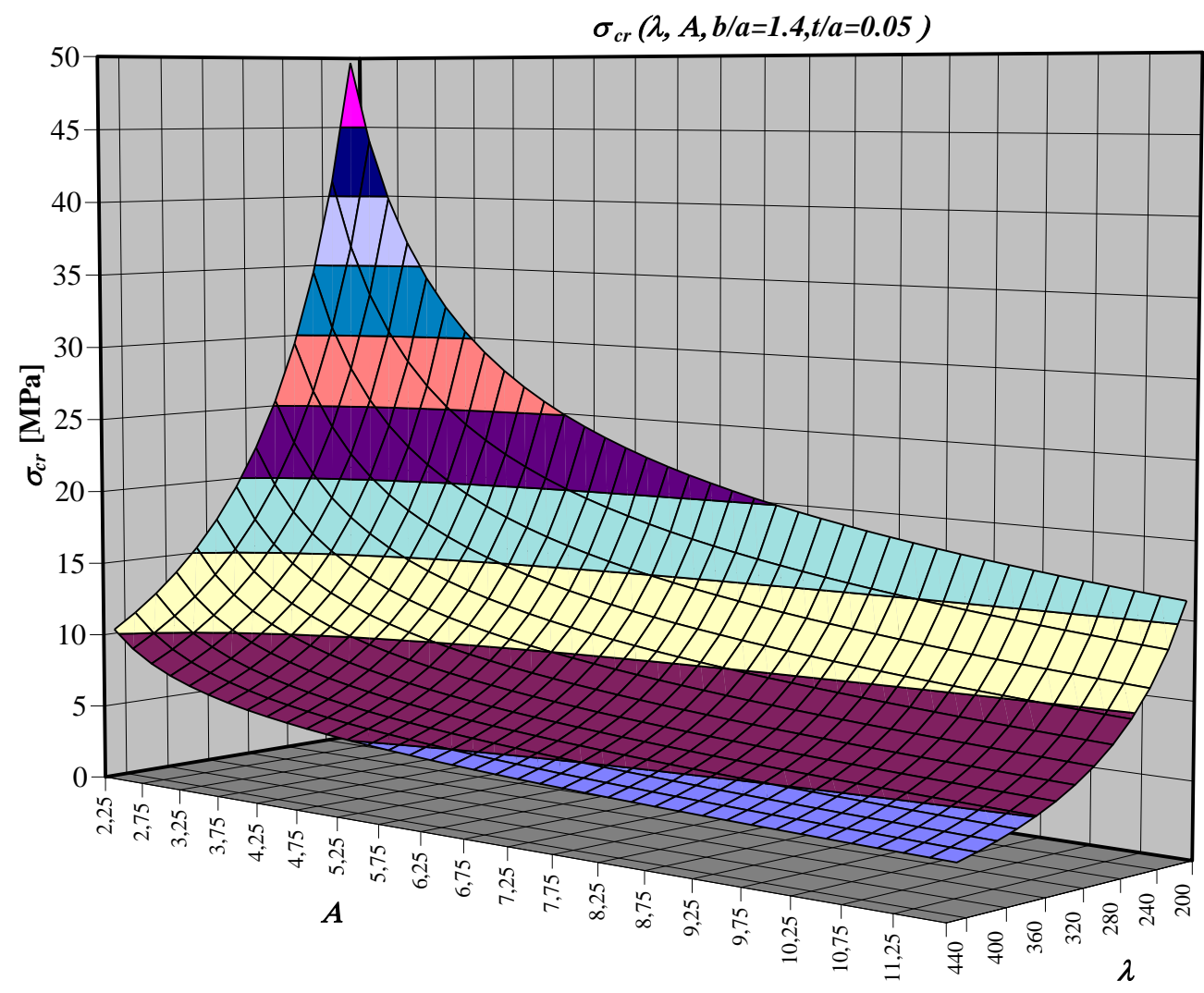

(a) 


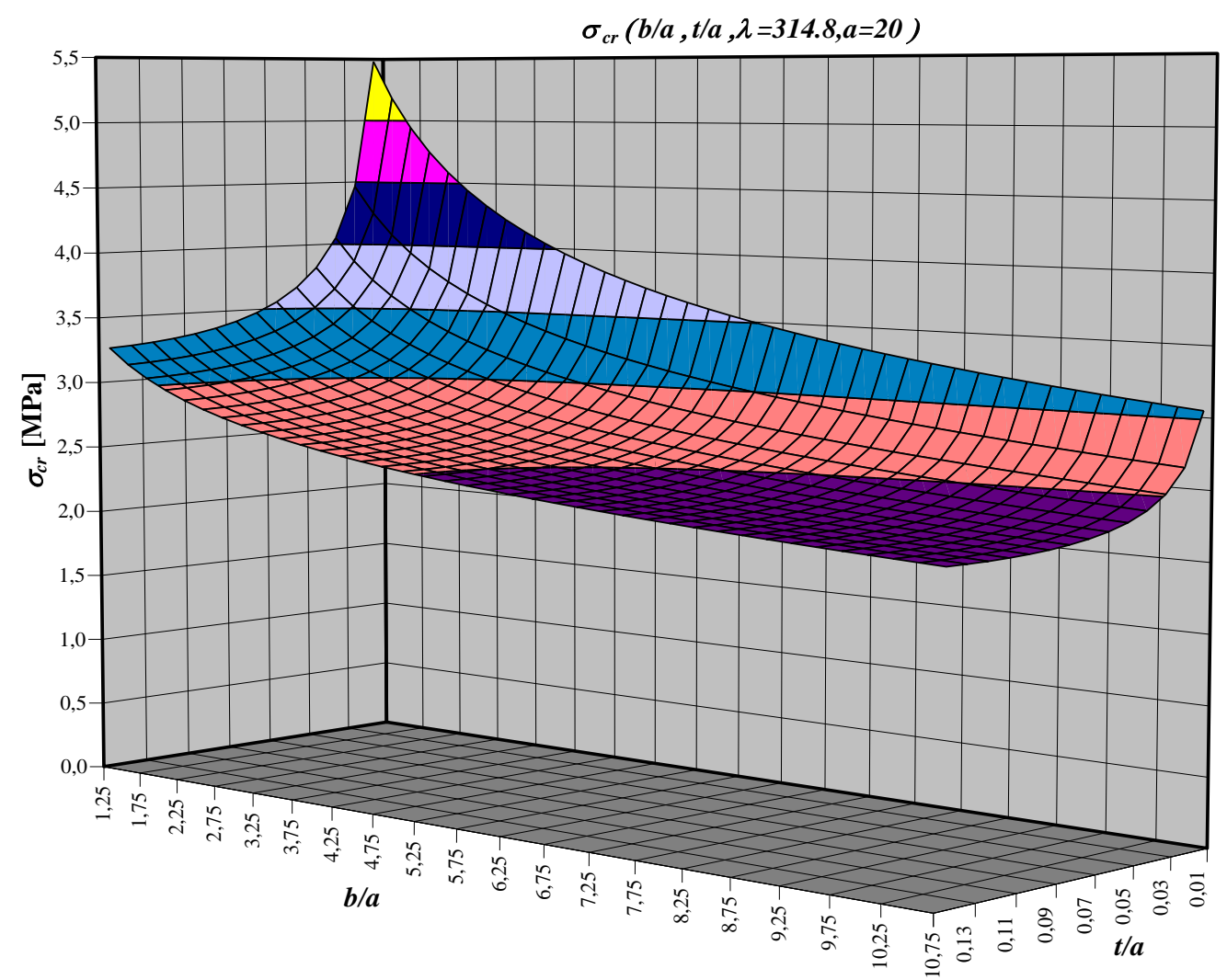

(b)

Fig. 4: Surface functions of critical stress for axially compressed (by force through ball-and-socket joints) rectangular shaped shells made of steel, according to the technical stability theory

The focus in Fig. 3 is given to:

a) The critical stress that is shown in Fig. 3a, as a function of the cross sectional area $A$ and slenderness ratio $\lambda$ at $a / b=\operatorname{cost}$ and $t / b=\operatorname{cost}$

b) The function shown in Fig. $3 \mathrm{~b}$ is the same of Fig. 3a, but the parameters $\mu=a / t, \zeta=b / t$ and $\chi=a / L$ are used under the condition that $t=$ cost

c) The same function is shown in Fig. 3c, with the exception that $t=$ cost with the parameter $\mu$ constant, but with $\chi$ and $\mu$ modify

d) Finally, the function is shown in Fig. 3d with constant parameters $\mu=a / t$ and $\zeta=b / t$, but variable $\chi$ and $t$

The critical stress can be described also by the empirical formulas presented in Fig. 4.

For thin walled columns $(t>0)$, the corresponding formulas for the critical stress analysis are presented in Fig. 5. Again, the sensitivity of critical stress is shown as a function of:

a) the cross sectional area $A$ and slenderness ratio $\lambda$ at $a / b=$ cost b) slenderness ratio $\lambda$ and $L / a=$ var at $a / b=$ cost

For comparative purposes, the Euler's formulas of critical stresses for rectangular columns in the dependence on $\mu, \chi, \zeta$ and $t$ are then presented in Fig. 6 . More in detail, the analysis is proposed as a function of:

a) The slenderness ratio $\lambda$

b) The parameters $\mu=a / t=$ var, $\chi=a / L=\operatorname{var}, \zeta=$ $b / t=$ cost

c) The parameters $\zeta=b / t=$ var, $\chi=a / L=$ var, $\mu=$ $a / t=$ cost

d) And finally the parameters $t=\operatorname{var}, L=$ var, $a=$ cost, with $b=$ cost

In the case of the reference rectangular column ( $a=$ $20 \mathrm{~mm}, b=28 \mathrm{~mm}, t=1 \mathrm{~mm}, L=2500 \mathrm{~mm}$ ) the critical stress according to Euler's theory is calculated in $\sigma_{c r}^{\text {Euler }}(\lambda)=16.592 \mathrm{MPa}$. The reference value of Young's modulus is set in $E=166600 \mathrm{MPa}$, according to past stability studies on thin walled columns (Murawski, 2011). In this regard, the critical stress for the same column, according to the technical stability theory, is predicted in $\sigma_{c r}^{\text {balls }}$ rectangular $(\lambda, A, a / b, t / b)=3.562 \mathrm{MPa}$. 
Krzysztof Murawski / International Journal of Structural Glass and Advanced Materials Research 2020, Volume 4: 186.208 DOI: $10.3844 /$ sgamrsp.2020.186.208

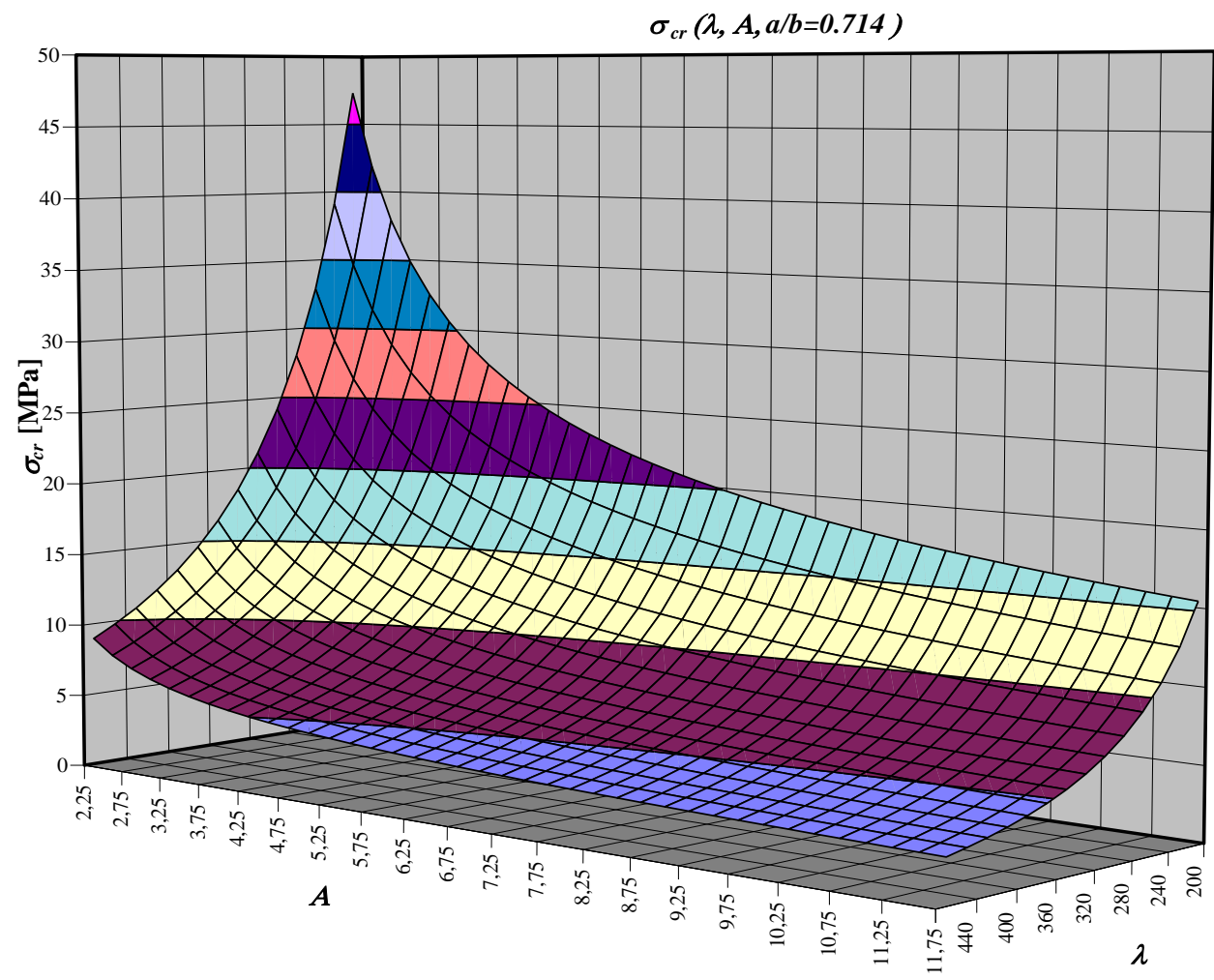

(a)

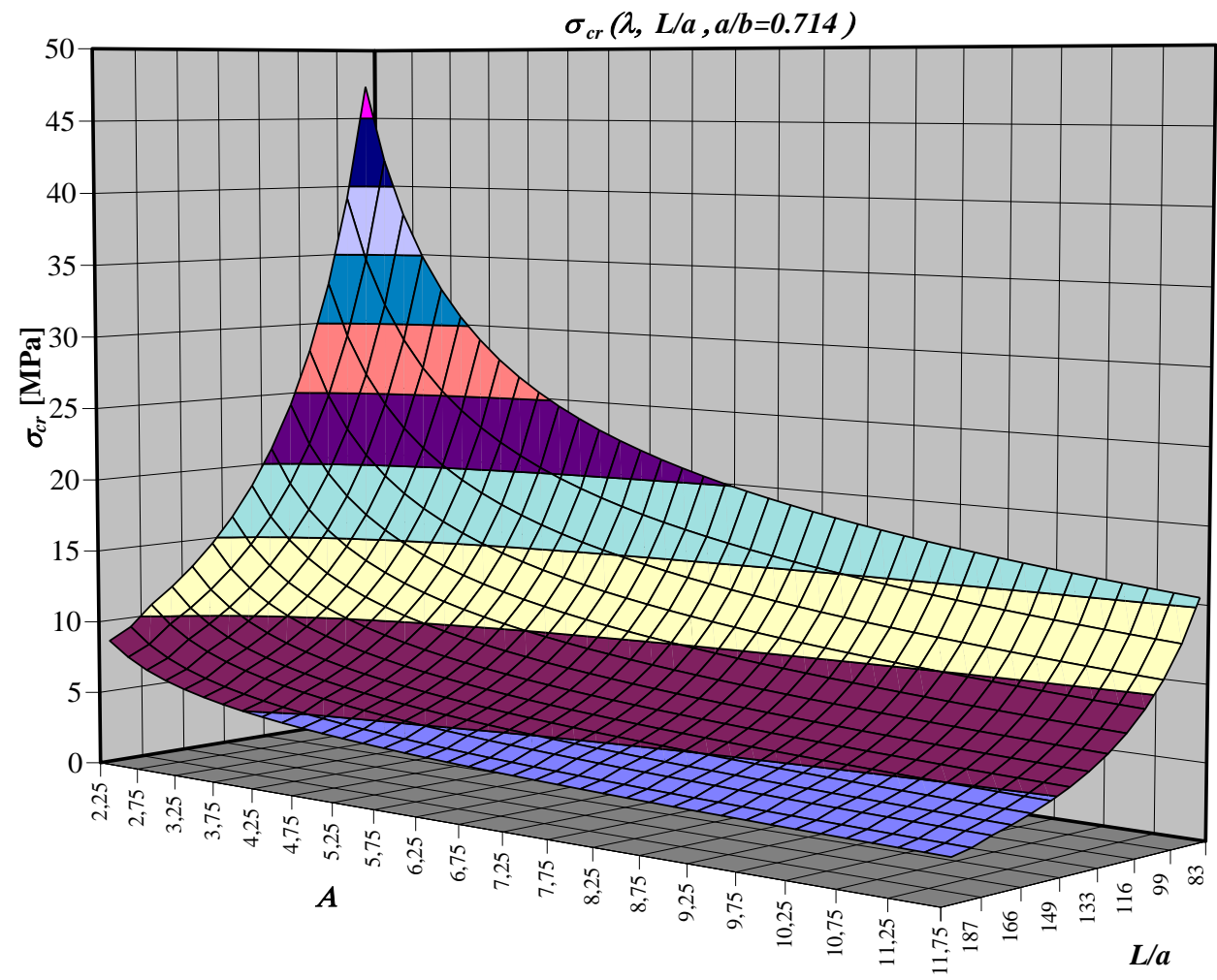

(b)

Fig. 5: Surface functions of the critical stress of axially compressed (by force through ball-and-socket joints) rectangular shaped shells made of steel, according to the technical stability theory 
Krzysztof Murawski / International Journal of Structural Glass and Advanced Materials Research 2020, Volume 4: 186.208 DOI: $10.3844 /$ sgamrsp.2020.186.208

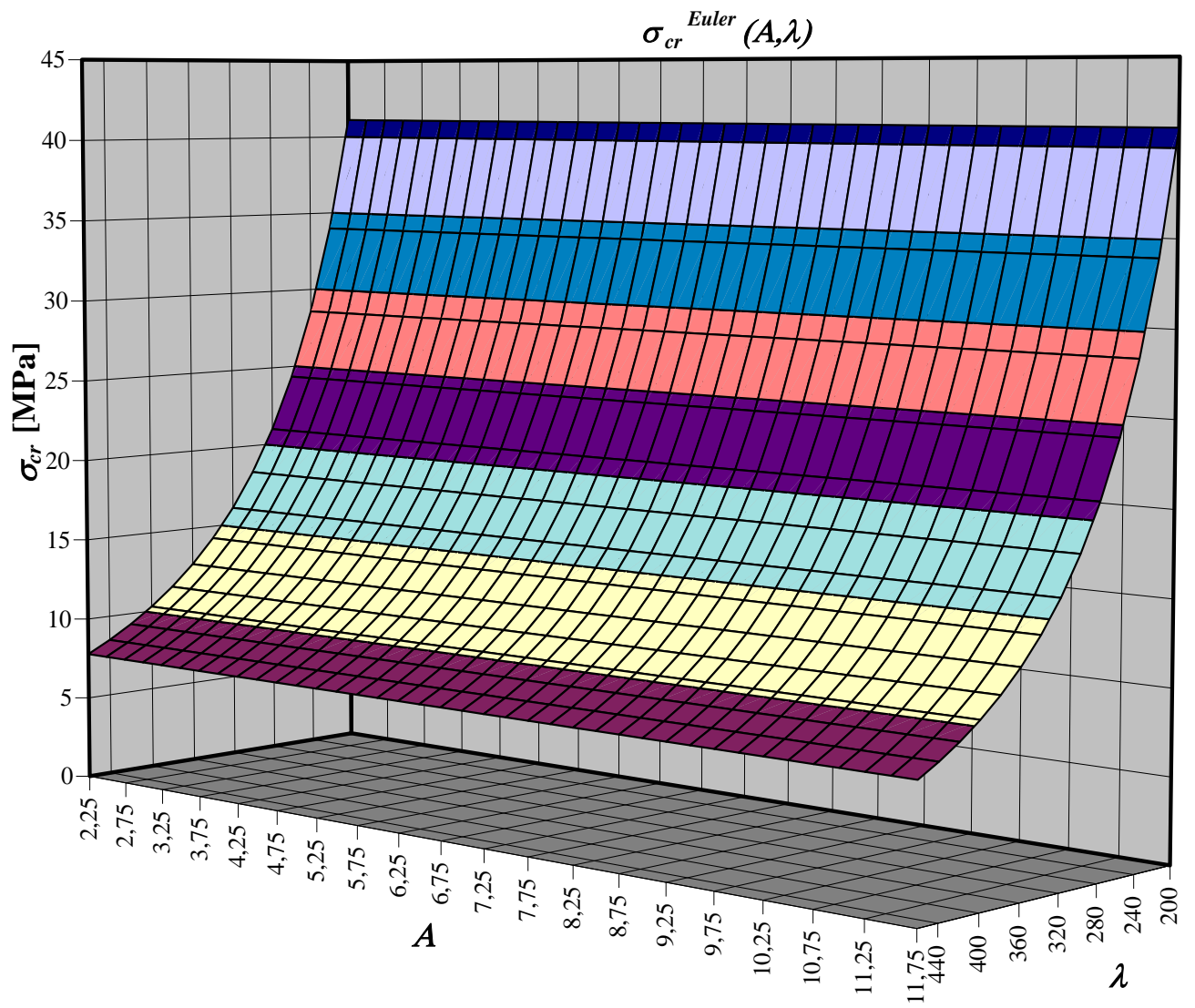

(a)

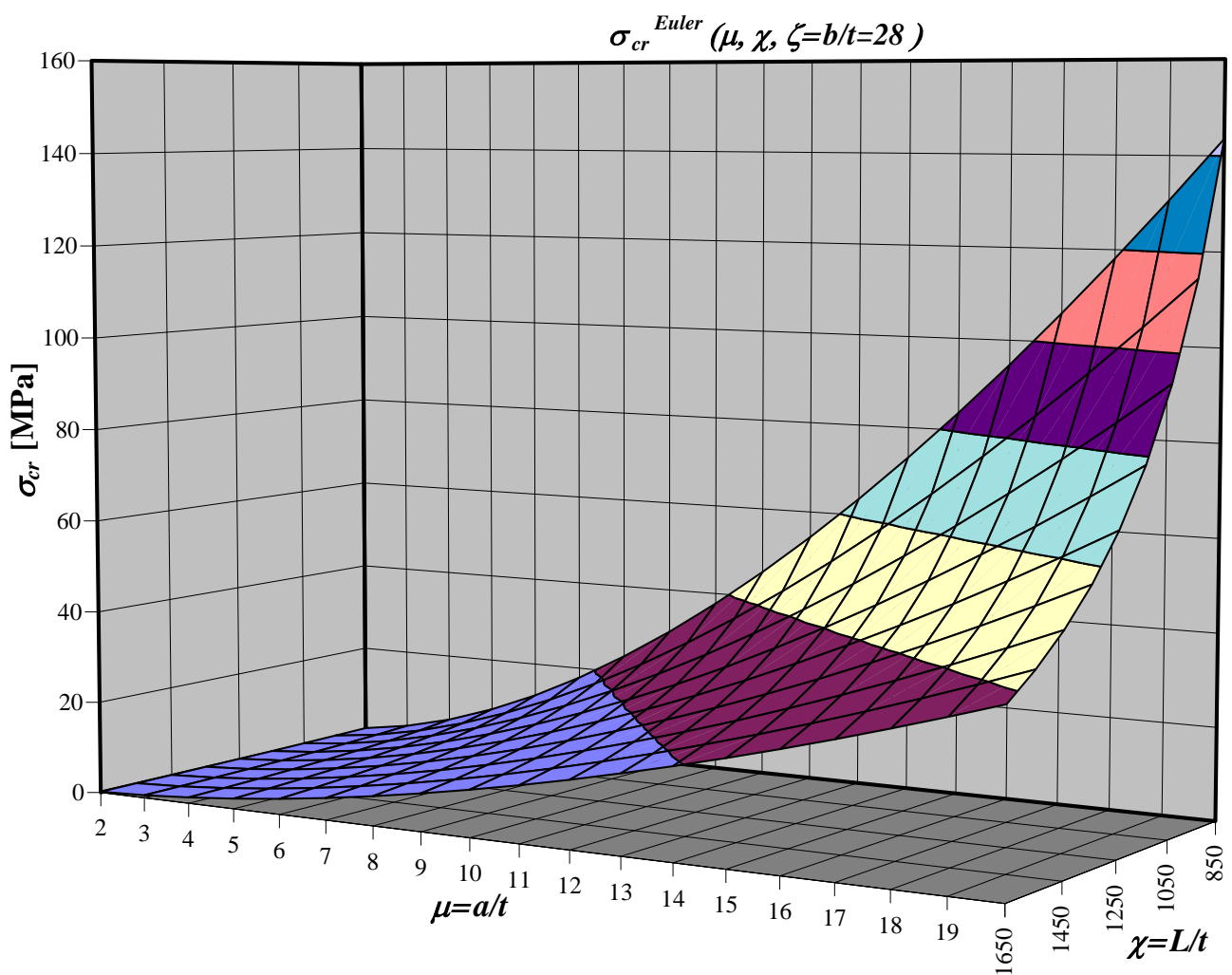

(b) 
Krzysztof Murawski / International Journal of Structural Glass and Advanced Materials Research 2020, Volume 4: 186.208 DOI: $10.3844 /$ sgamrsp.2020.186.208

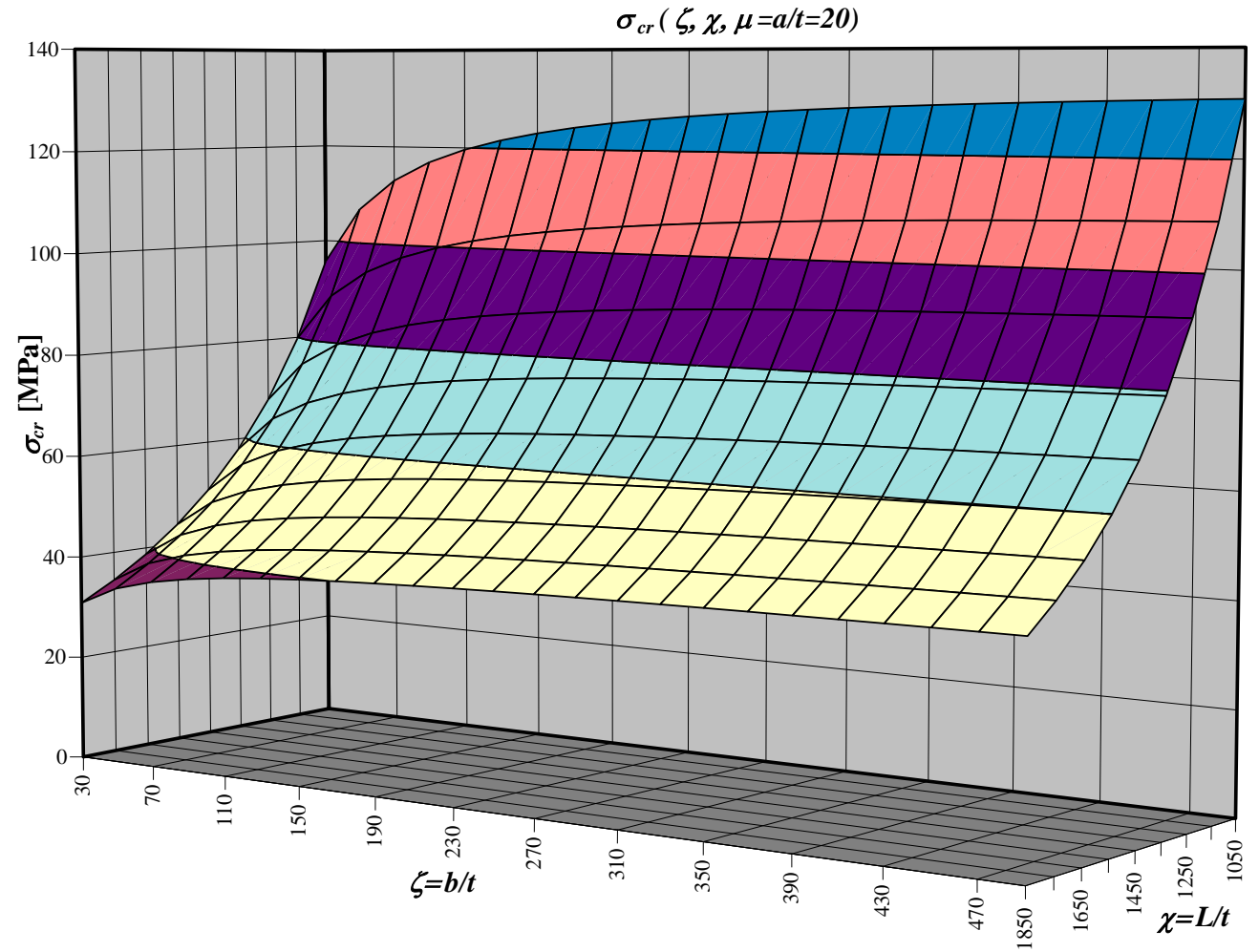

(c)

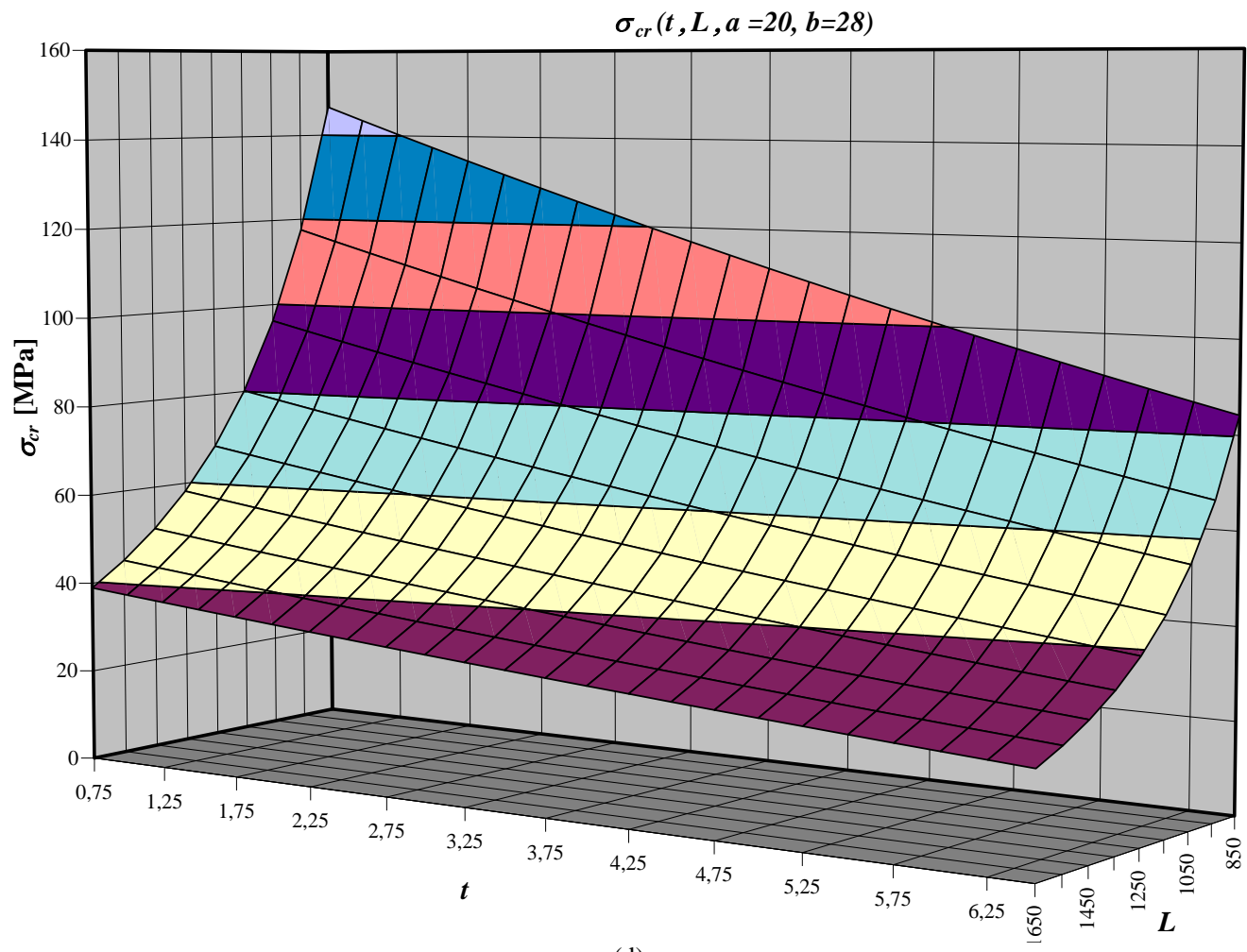

(d)

Fig. 6: Surface function of the critical stress based on Euler's formulation of rectangular shaped shells made of steel and axially compressed by force through ball-and-socket joints 


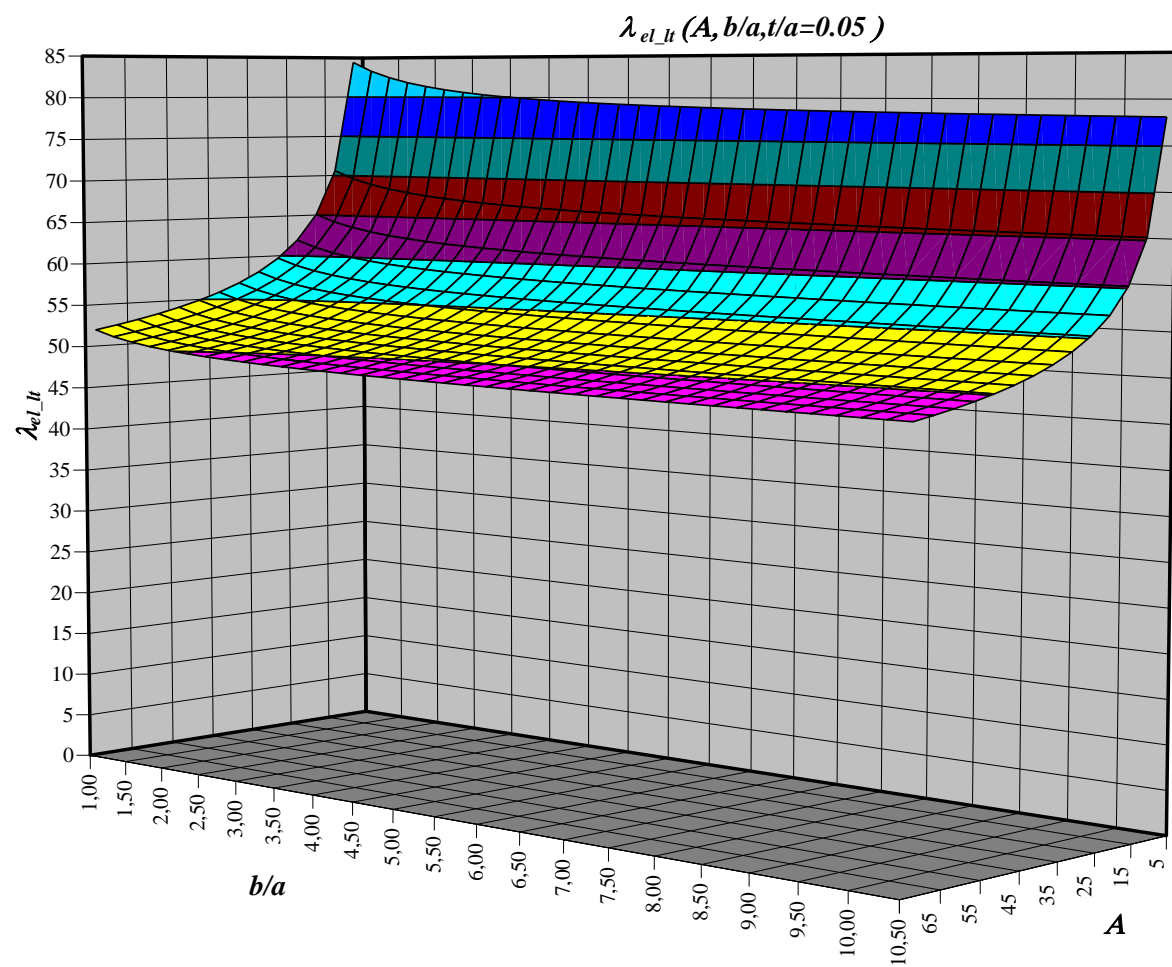

(a)

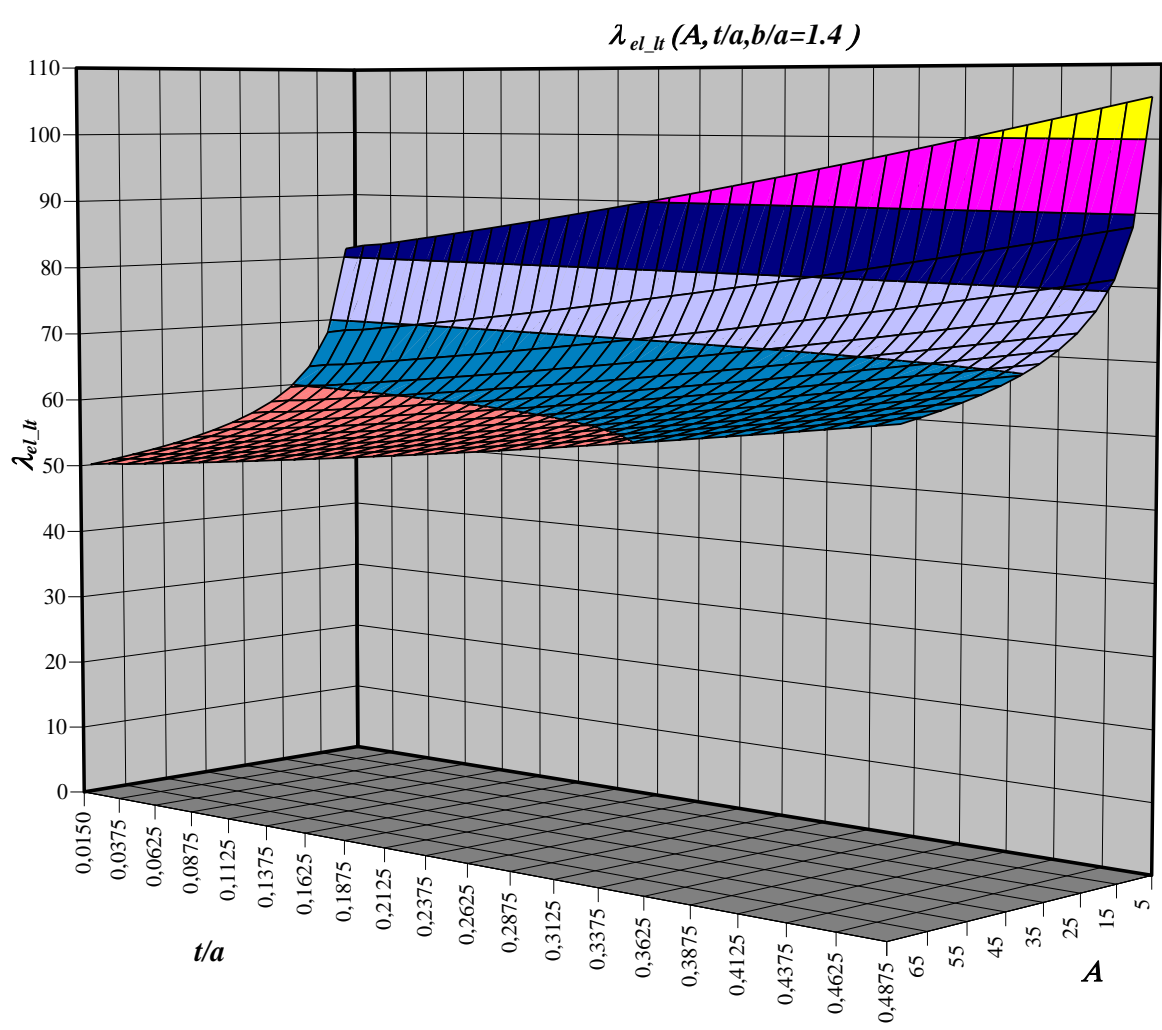

(b)

Fig. 7: Surface function of the limited slenderness ratio $\lambda_{\text {el-lt }}$ based on the technical stability formula of rectangular shaped shells made of steel in dependence on (a) cross-sectional area $A$, ratio $b / a=$ var and $t / a=$ cost, (b) cross section area $A$, ratio $t / a=$ var and $b / a=$ cost 


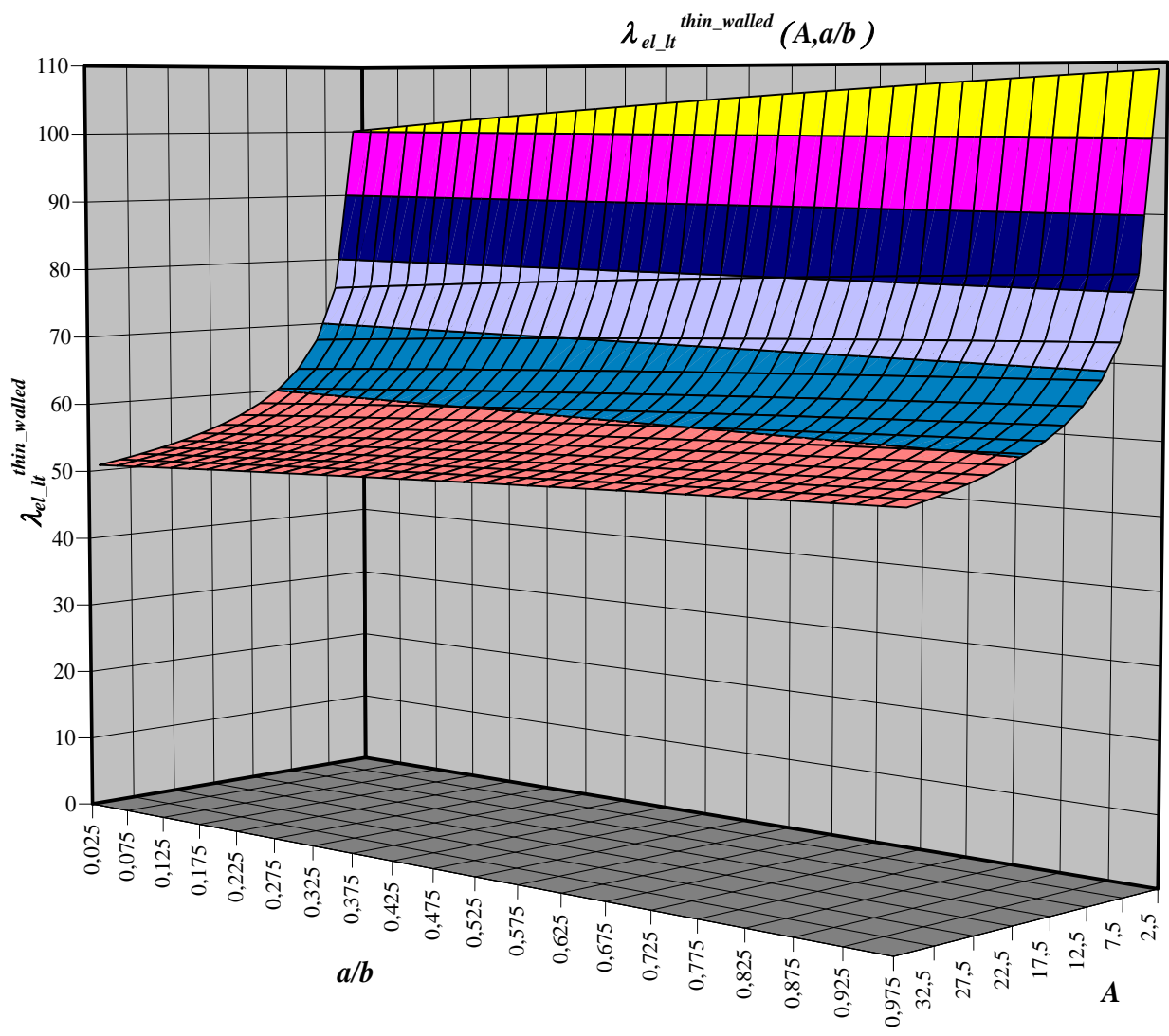

Fig. 8: Surface function of limited slenderness ratio $\lambda_{\text {el-lt }}$, based on the technical stability formulation, of thin walled rectangular columns made of steel, in dependence on $A$ and $a / b=$ var

Since the described phenomenon occurs in an elastic state for steel shells, it is thus expected that their slenderness ratio should be at least $\lambda>\lambda_{\text {ell-lt}}$, according to Euler's theory.

The limited slenderness ratio $\lambda_{\text {ellt }}$ is then calculated according to the technical stability theory in Fig. 7. For thin walled columns the formula for the limited slenderness ratio $\lambda_{\text {el-lt }}^{\text {thin_walled }}$ can be also seen in Fig. 8 .

\section{Stress and Strain Analysis}

According to the technical stability theory, the state of stresses and strains in the shell belonging to the critical transverse section of a rectangular shaped column compressed by ball-and-socket joints, after the loss of stability, is as the result of a superposition of bending and pure compression (Fig. 1) and thus:

$$
\begin{aligned}
& \varepsilon_{n} \cdot E=\sigma_{n}=\sigma_{g}+\sigma_{c}= \pm \frac{y}{\rho} \cdot E-\frac{P}{A} \\
& =E \cdot\left( \pm \frac{y}{\rho}-\frac{\Delta L}{L}\right)=E \cdot\left( \pm \varepsilon_{g}-\varepsilon_{c}\right)=>
\end{aligned}
$$

with:
$\Rightarrow \varepsilon_{n}= \pm \varepsilon_{g}-\varepsilon_{c}$.

It results that the shell normal stress $\sigma_{n}$ is like Equation (71) in (Murawski, 2011), or Equation (2.19) from (Murawski, 2018):

The graphs of the functions of the normal shell stress $\sigma_{n}$, normal strain $\varepsilon_{n}$, transverse stress $\sigma_{y}$ and transverse strain $\varepsilon_{y}$ in the selected rectangular column $(a=20 \mathrm{~mm}$, $b=28 \mathrm{~mm}, t=1 \mathrm{~mm}, L=2500 \mathrm{~mm}$ ), axially compressed by force through ball-and-socket joints, are presented in Figs. 9, 11 and 13.

The stresses and strains are proposed in dependence of $x$ and $y$, where $x=0 \div L$ and $y=-a / 2,-a / 4,-a / 20,0.0$, $a / 20, a / 4, a / 2$, respectively.

The graphs of the functions of the normal stress $\sigma_{n_{-} x=L / 2}(y)$, normal strain $\varepsilon_{n_{-} x=L / 2}(y)$, transverse stress $\sigma_{y_{-} x=L / 2}(y)$ and transverse strain $\varepsilon_{y_{-} x=L / 2}(y)$ in the critical cross-section $(x=L / 2)$, depending on $y$ and $x$, are presented in Figs. 10, 12 and 14 for load values set in $P=$ $0.1,0.5$, or $1.0 P_{\text {cr. }}$.

The graphs of the function of the coordinate $y_{\sigma n=0}$, $x=L / 2(P)$ of a zero normal stress $\sigma_{n_{-} x=L / 2}(y)=0$ in the critical cross-section $(x=L / 2)$ in dependence on the load 
$P$ are presented in Fig. 15a and the graphs of the function of the deformation $\Delta L_{x=L / 2, y=a / 2}(P)$ in the critical (middle) cross-section $(x=L / 2)$ of the rectangular shaped steel shell on two opposite generating lines $(y= \pm a / 2)$ in dependence on the load $P$ is presented in Fig. 15b. As also previously described, the values of Young's modulus $E=166600 \mathrm{MPa}$ and Poisson's ratio $v=0.3$ were taken into account for calculations.

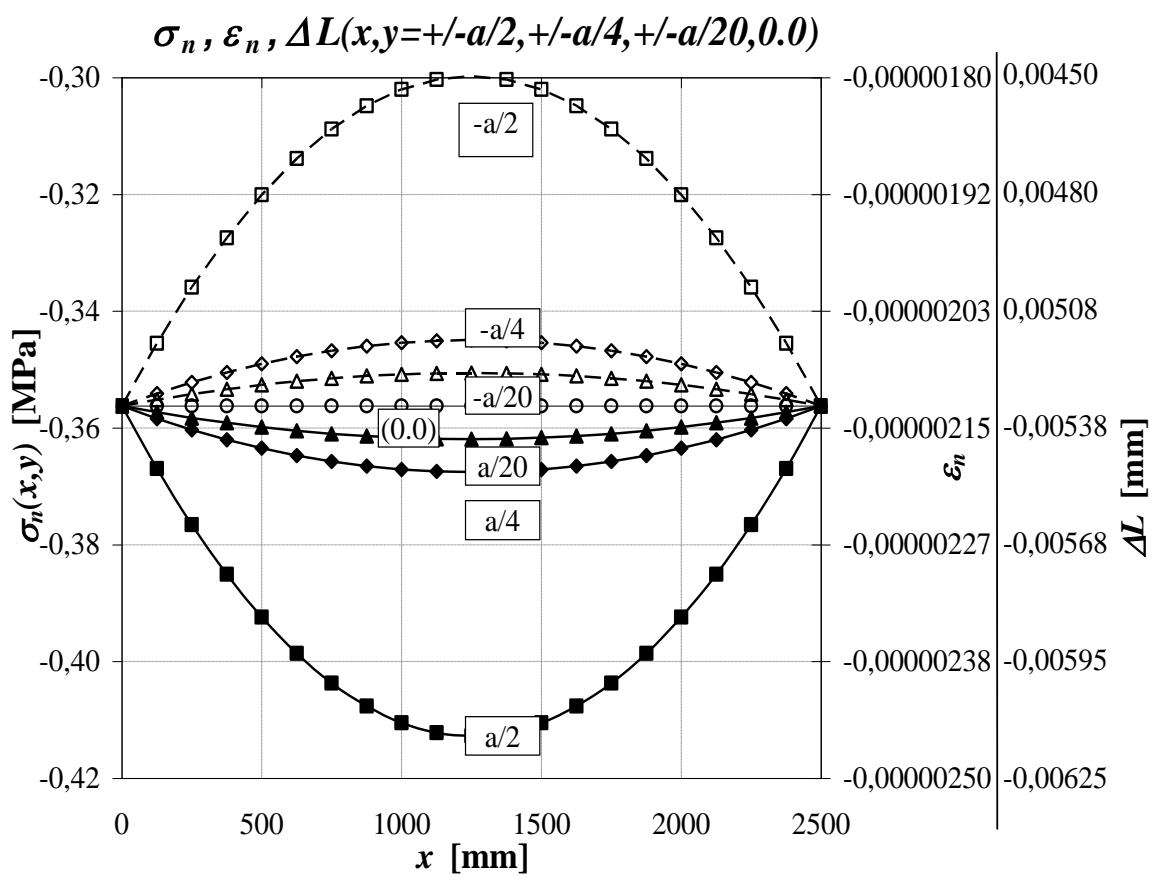

(a)

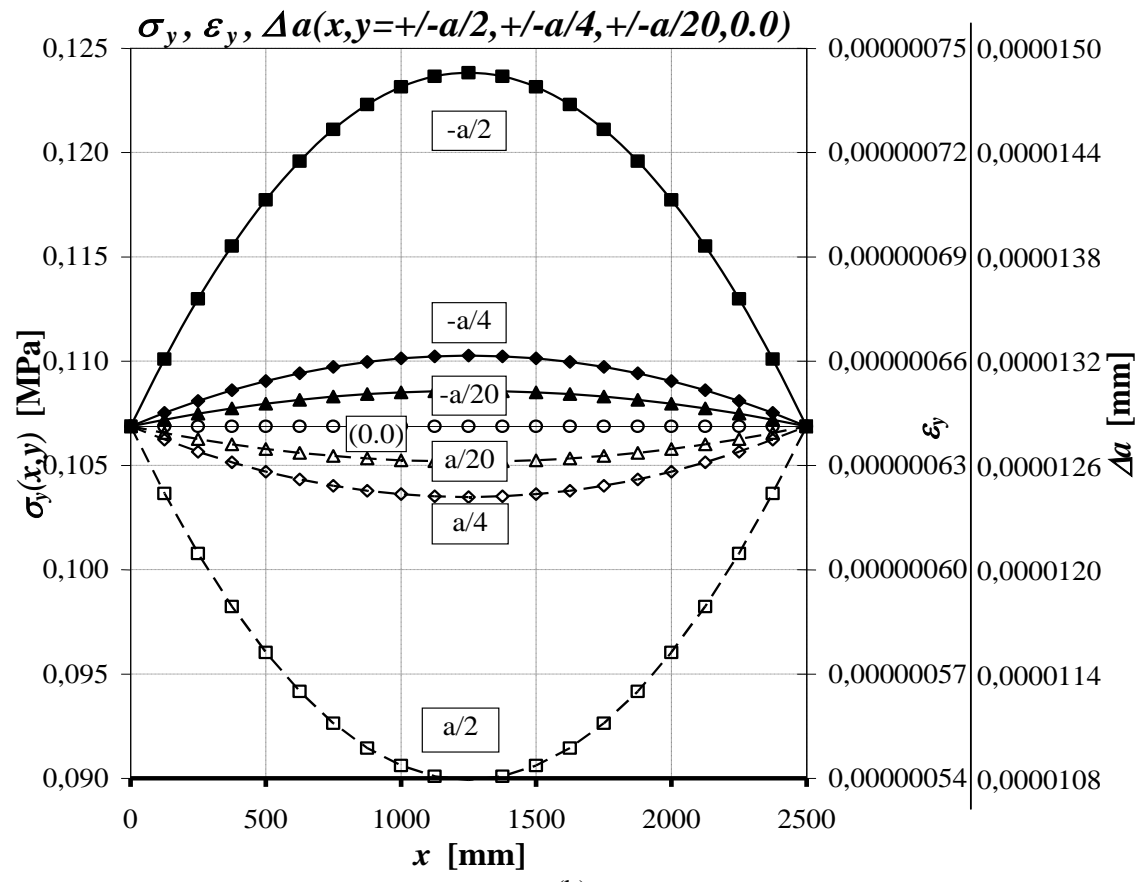

(b)

Fig. 9: Values of (a) stress $\sigma_{n}(x, y)$, strain $\varepsilon_{n}(x, y)$, deformation $\Delta L(x, y)$ and (b) stress $\sigma_{y}(x, y)$, strain $\varepsilon_{y}(x, y)$, deformation $\Delta a(x, y)$ where $x=0 \div L$ and $y=-a / 2,-a / 4,-a / 20,0.0, a / 20, a / 4, a / 2$ respectively, for $P=0.1 P_{c r}$ in a rectangular steel shell (dimensions: $a=$ $20 \mathrm{~mm}, b=28 \mathrm{~mm}, t=1 \mathrm{~mm}, L=2500 \mathrm{~mm}$ ) compressed by ball-and-socket joints 
Krzysztof Murawski / International Journal of Structural Glass and Advanced Materials Research 2020, Volume 4: 186.208 DOI: $10.3844 /$ sgamrsp.2020.186.208

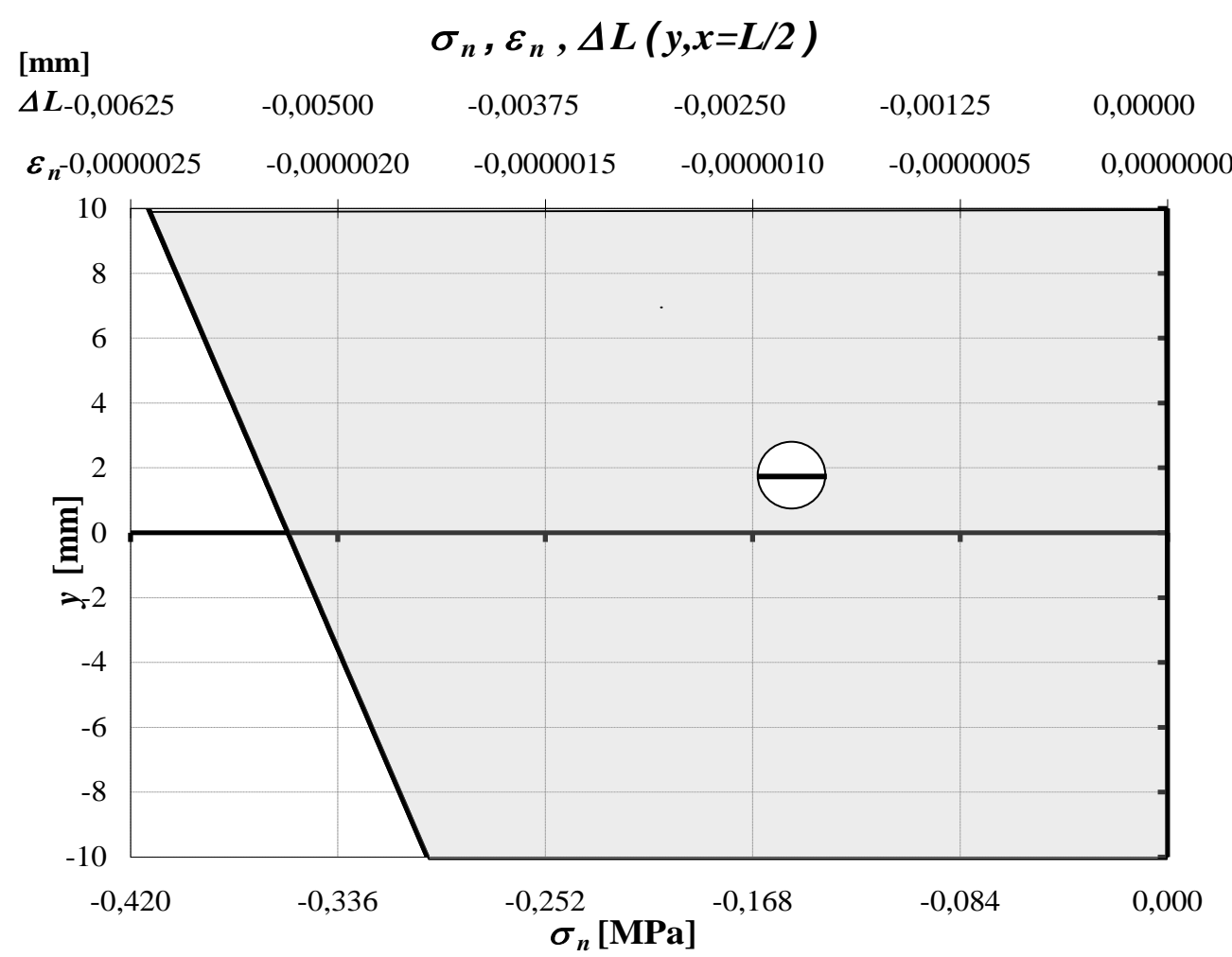

(a)

\begin{tabular}{|c|c|c|c|c|c|}
\hline [mm] & \multicolumn{4}{|c|}{$\sigma_{y}, \varepsilon_{y}, \Delta a(y, x=L / 2)$} & \multirow[b]{2}{*}{0,00625} \\
\hline$\Delta a 0,00000$ & 0,00125 & 0,00250 & 0,00375 & 0,00500 & \\
\hline $\boldsymbol{\varepsilon}_{\boldsymbol{y}} \quad 0,0000000$ & 0,0000005 & 0,0000010 & 0,0000015 & 0,0000020 & 0,0000025 \\
\hline
\end{tabular}

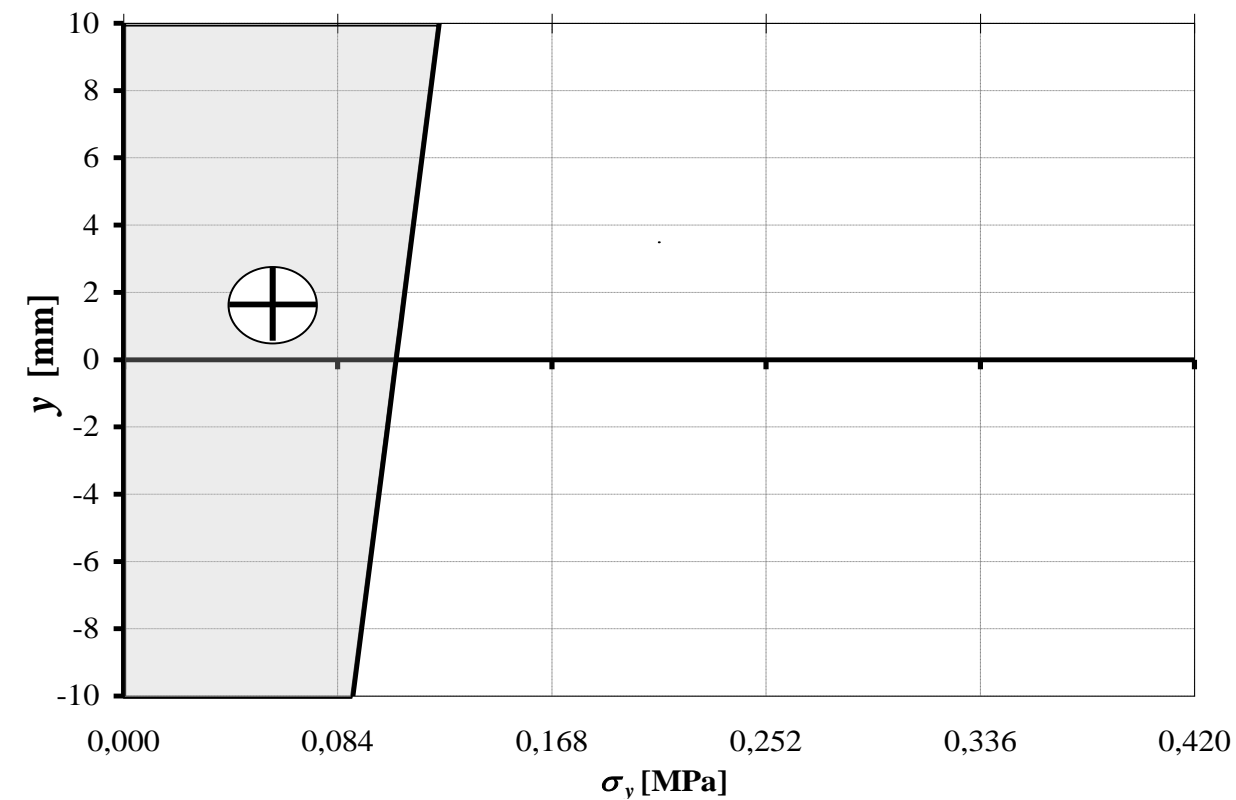

(b)

Fig. 10: Values of (a) normal stress-strain-deformation $\sigma_{n}, \varepsilon_{n}, \Delta L(y, x=L / 2)$ and (b) transverse stress-strain-deformation $\sigma_{y}, \varepsilon_{y}, \Delta 2 t(y, x$ $=L / 2$ ) for $P=0.1 P_{c r}$ in a rectangular steel shell (dimensions: $a=20 \mathrm{~mm}, b=28 \mathrm{~mm}, t=1 \mathrm{~mm}, L=2500 \mathrm{~mm}$ ) compressed by ball-and-socket joints 


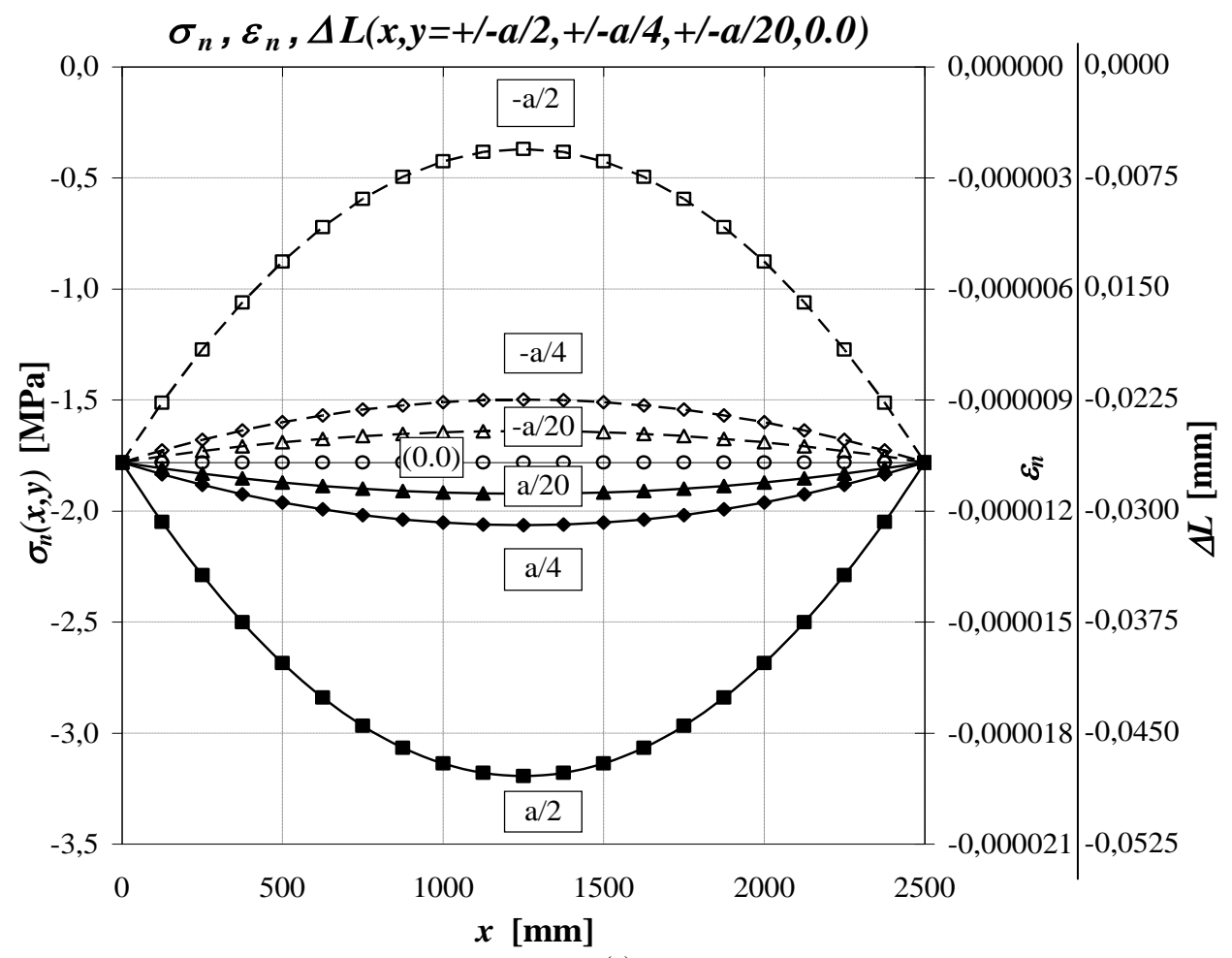

(a)

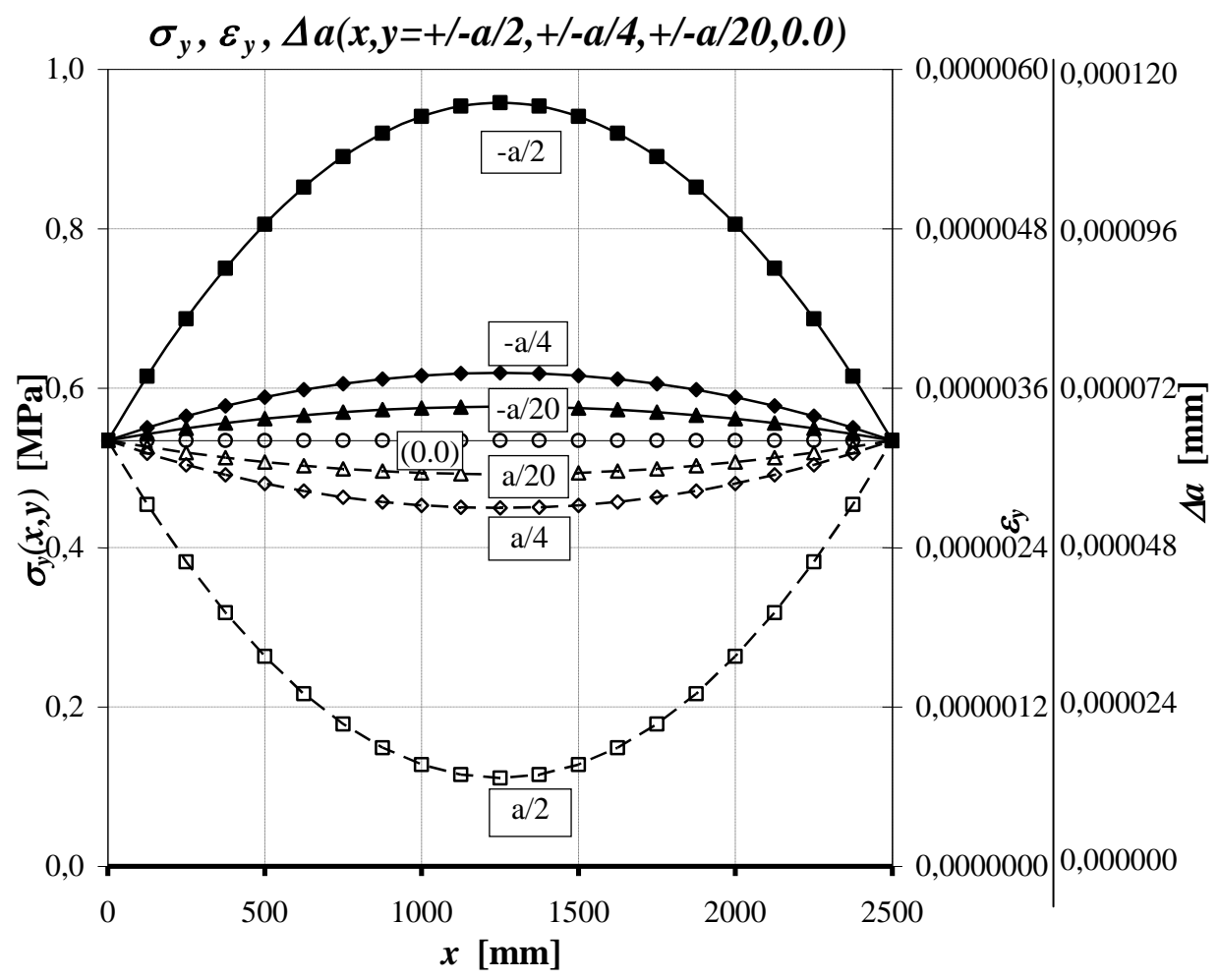

(b)

Fig. 11: Values of (a) stress $\sigma_{n}(x, y)$, strain $\varepsilon_{n}(x, y)$, deformation $\Delta L(x, y)$ and (b) stress $\sigma_{y}(x, y)$, strain $\varepsilon_{y}(x, y)$, deformation $\Delta a(x, y)$ (where $x=0 \div L$ and $y=-a / 2,-a / 4,-a / 20,0.0, a / 20, a / 4, a / 2$ respectively) for an imposed load value $P=0.5 P c r$, in a rectangular steel shell (dimensions: $a=20 \mathrm{~mm}, b=28 \mathrm{~mm}, t=1 \mathrm{~mm}, L=2500 \mathrm{~mm}$ ) compressed by ball-and-socket joints 


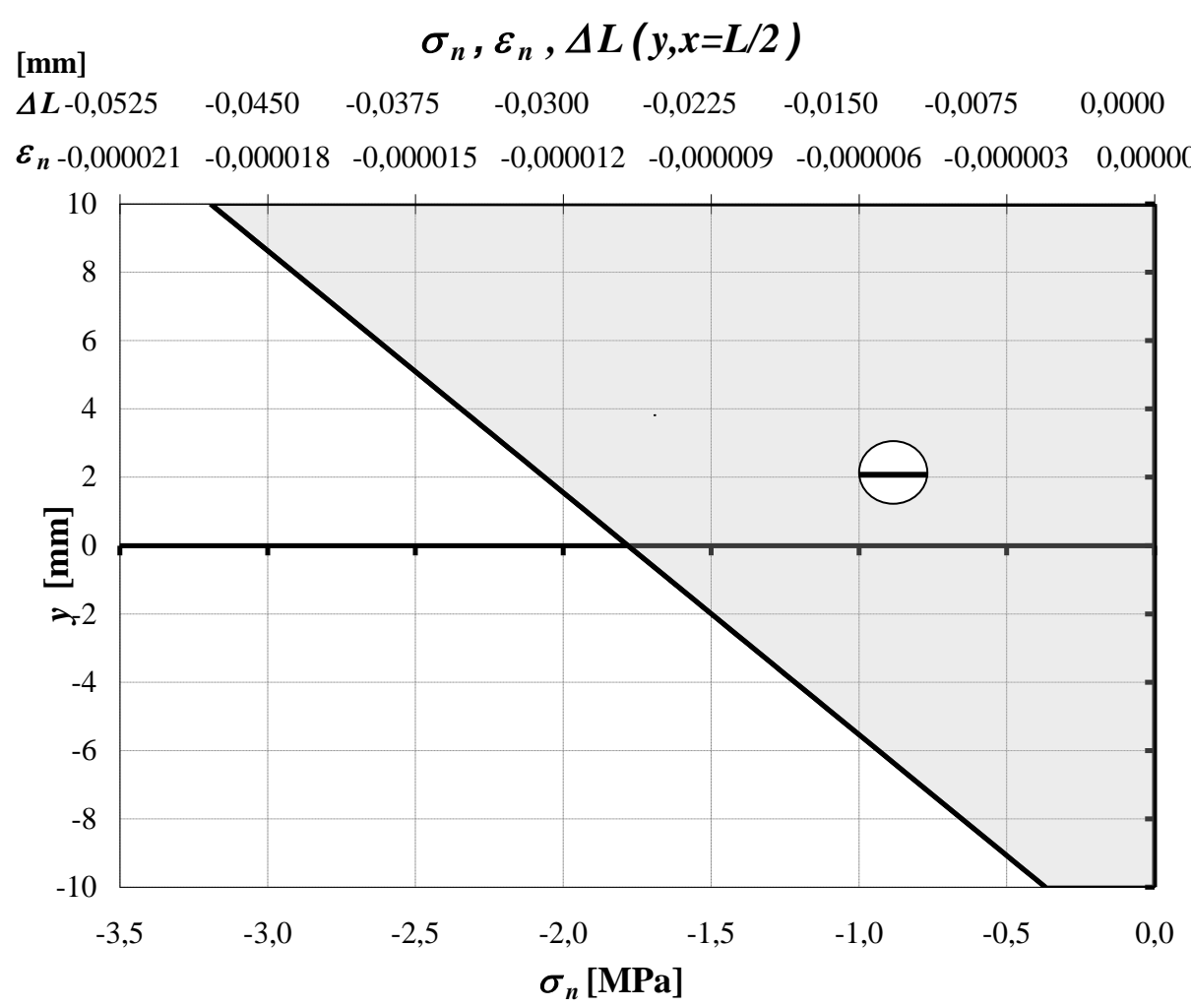

(a)

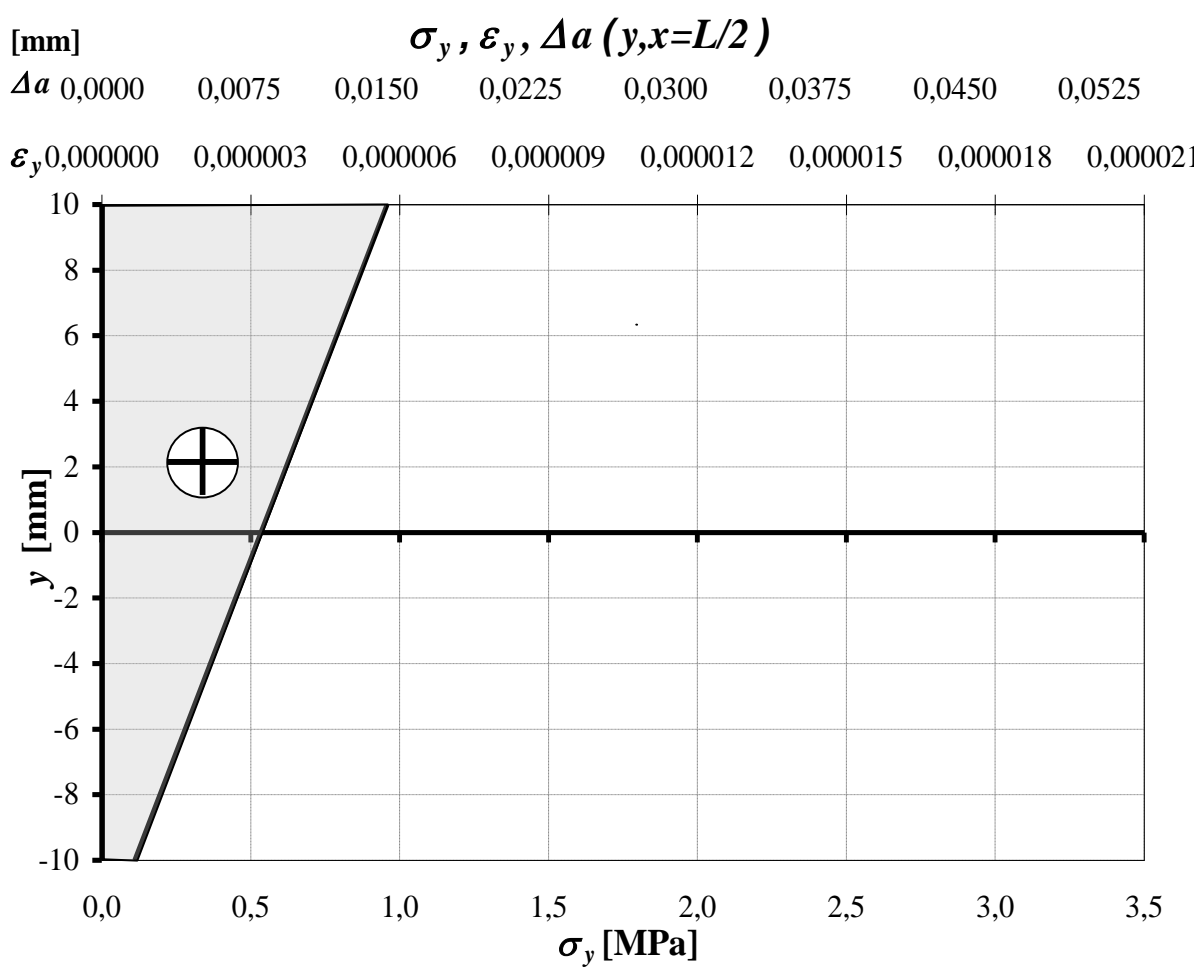

(b)

Fig. 12: Values of (a) normal stress-strain-deformation $\sigma_{n}, \varepsilon_{n}, \Delta L(y, x=L / 2)$ and (b) transverse stress-strain-deformation $\sigma_{y}, \mathcal{E}_{y}, \Delta 2 t(y, x$ $=L / 2$ ) for $P=0.5 P_{c r}$, in a rectangular shell made of steel (dimensions: $a=20 \mathrm{~mm}, b=28 \mathrm{~mm}, t=1 \mathrm{~mm}, L=2500 \mathrm{~mm}$ ) compressed by ball-and-socket joints 


\section{Discussion of Results}

The main conclusion which can be drawn out from Fig. $3 \mathrm{a}$ is that in order to determine the critical stresses $\sigma_{c r}{ }^{\text {balls }}$ rectangular for general rectangular shaped shell elements, the slenderness ratio $\lambda$ is not sufficient. The critical stress estimates should be indeed related also to the cross-section area $A$ and to values of the section ratios $a / b$ and $t / b$.

For a given slenderness ratio $\lambda$ like in original Euler's formulation) it is possible to obtain many different values of the critical stress $\sigma_{c r}{ }^{\text {balls }}$ rectangular in dependence of the cross-section area $A$ and the ratios $a / b$ and $t / b$.

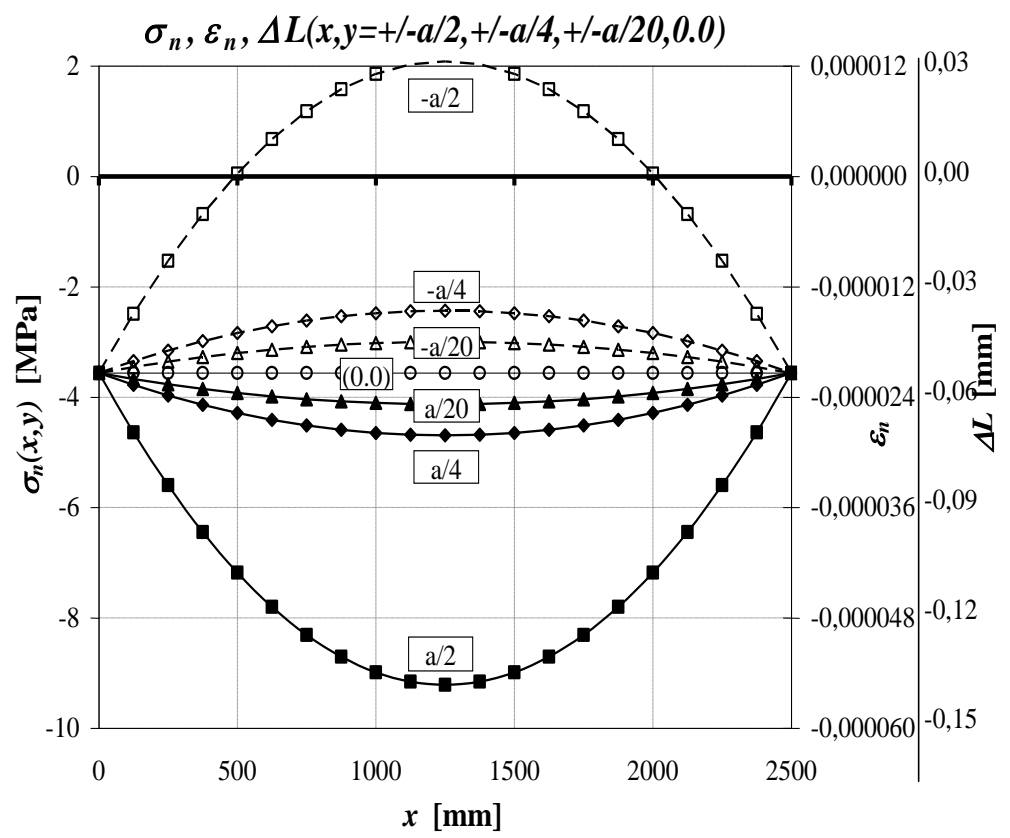

(a)

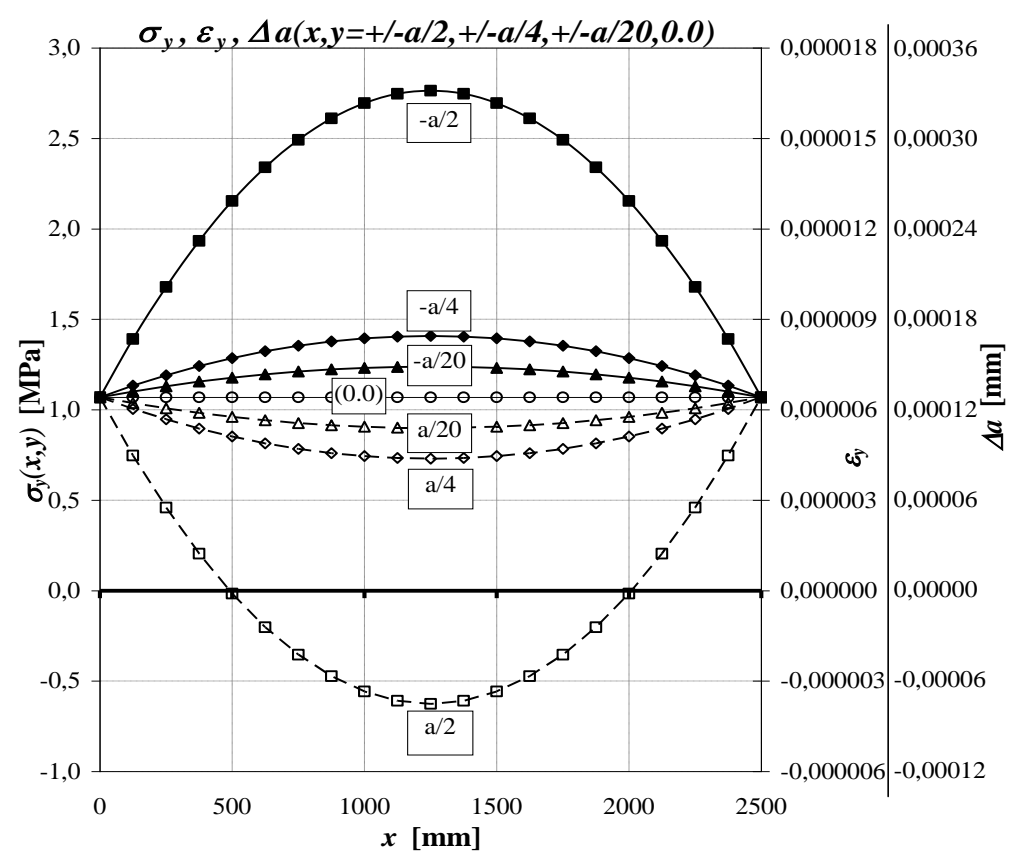

(b)

Fig. 13: Values of (a) stress $\sigma_{n}(x, y)$, strain $\varepsilon_{n}(x, y)$, deformation $\Delta L(x, y)$ and (b) stress $\sigma_{y}(x, y)$, strain $\varepsilon_{y}(x, y)$, deformation $\Delta a(x, y)$ for $P$ $=0.5 P_{c r}$, in a rectangular shell made of steel (dimensions: $a=20 \mathrm{~mm}, b=28 \mathrm{~mm}, t=1 \mathrm{~mm}, L=2500 \mathrm{~mm}$ ) compressed by ball-and-socket joints (where $x=0 \div \mathrm{L}$ and $y=-a / 2,-a / 4,-a / 20,0.0, a / 20, a / 4, a / 2$ respectively). 


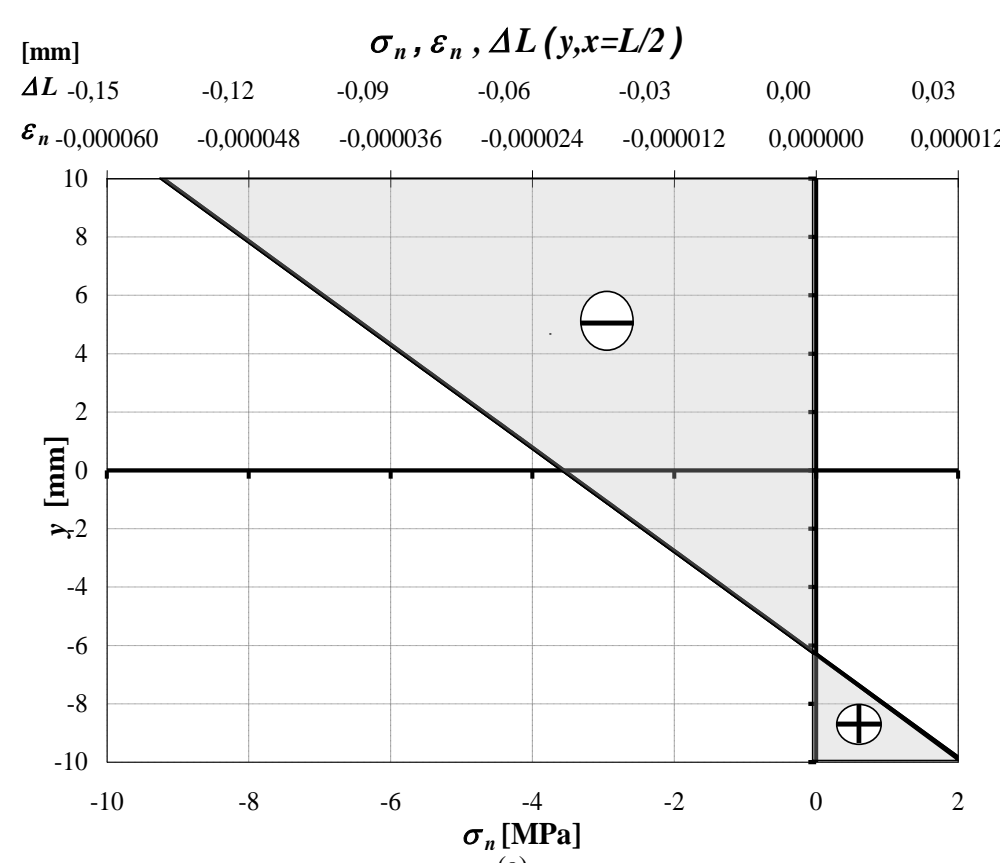

(a)

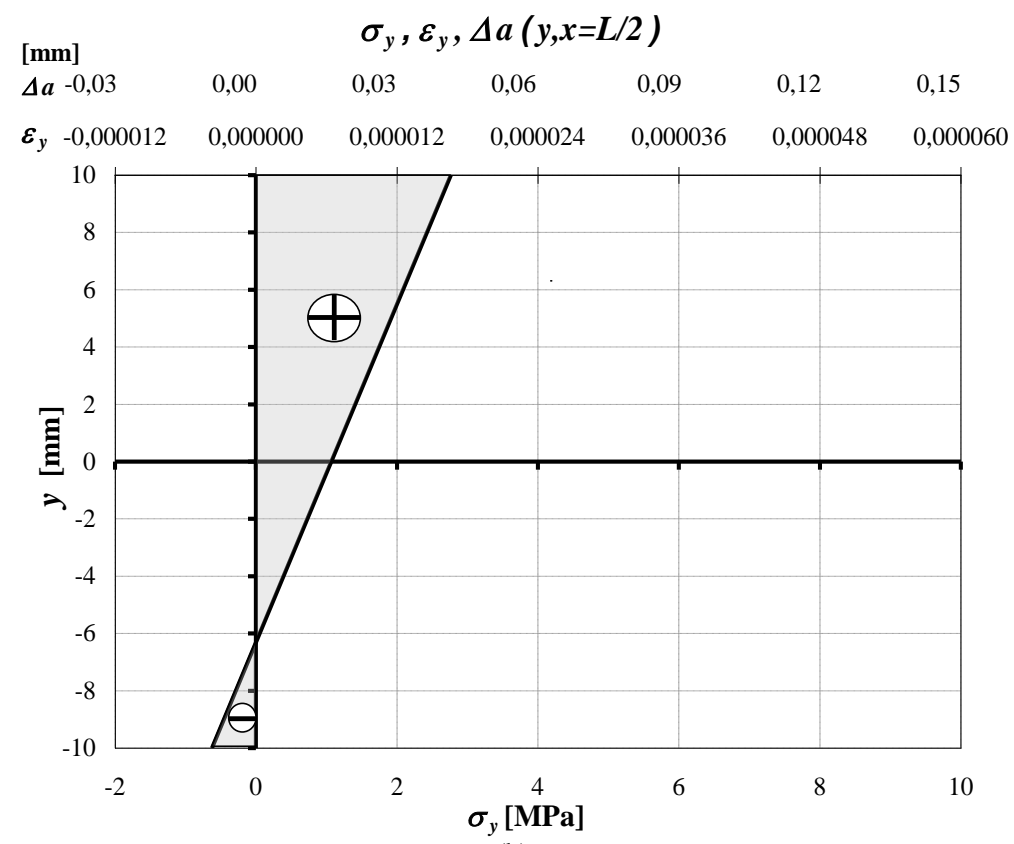

(b)

Fig. 14: Values of (a) normal stresses-strains $\sigma_{n}, \varepsilon_{n}, \Delta L(y, x=L / 2)$ and (b) transverse stress-strains $\sigma_{y}, \varepsilon_{y}, \Delta 2 t(y, x=L / 2)$ for $P=1.0$ $P_{c r}$ in a rectangular steel shell (dimensions: $a=20 \mathrm{~mm}, b=28 \mathrm{~mm}, t=1 \mathrm{~mm}, L=2500 \mathrm{~mm}$ ) compressed by ball-and-socket joints

The theoretical results, moreover, show that the simplifications used in the technical stability theory like taking under consideration only normal stresses, the assumption of flat cross-section planes and small slope of central line, involves certain limitations on its application in the engineering practice. The first of those limitations, for rectangular shaped shells, is that the cross-section area $A$ must be bigger than the unit.

Otherwise, the function approaches asymptotically to the vertical flat plane $A=1$ (Fig. 3a).

The surface function in Fig. 3a with $a / b=0.714, t / b=$ 0.0357 equals Euler's function $\sigma_{c r}$ Euler $(\lambda)$ for $A=2.6327$. 


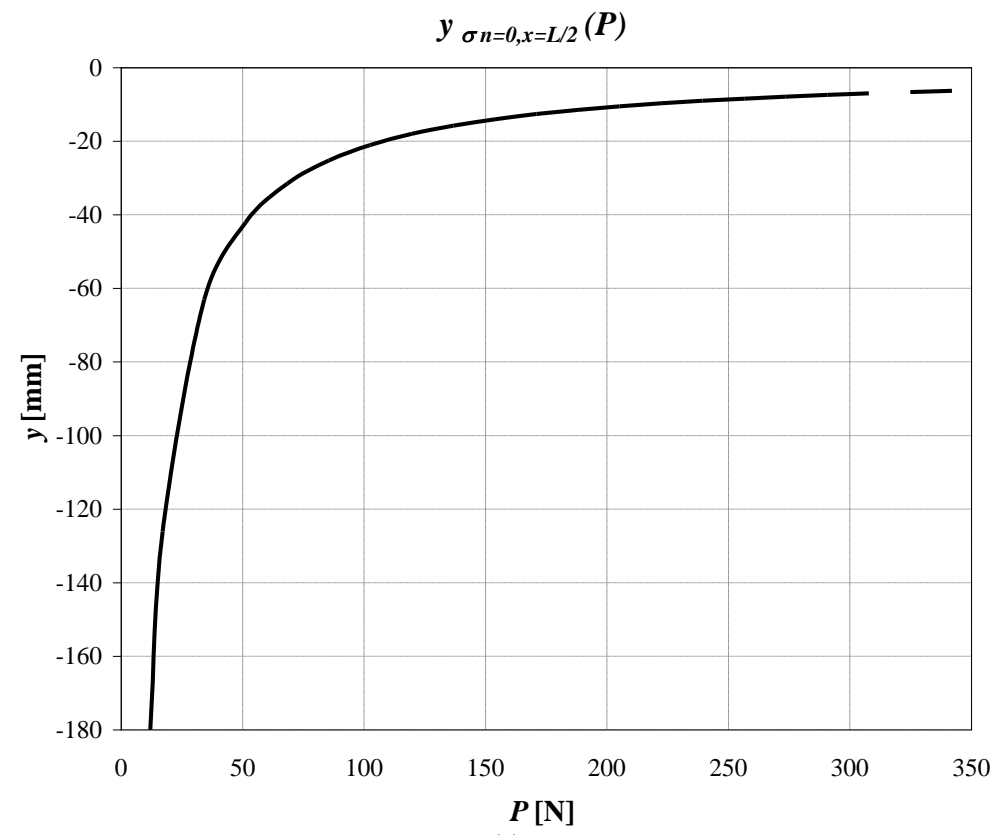

(a)

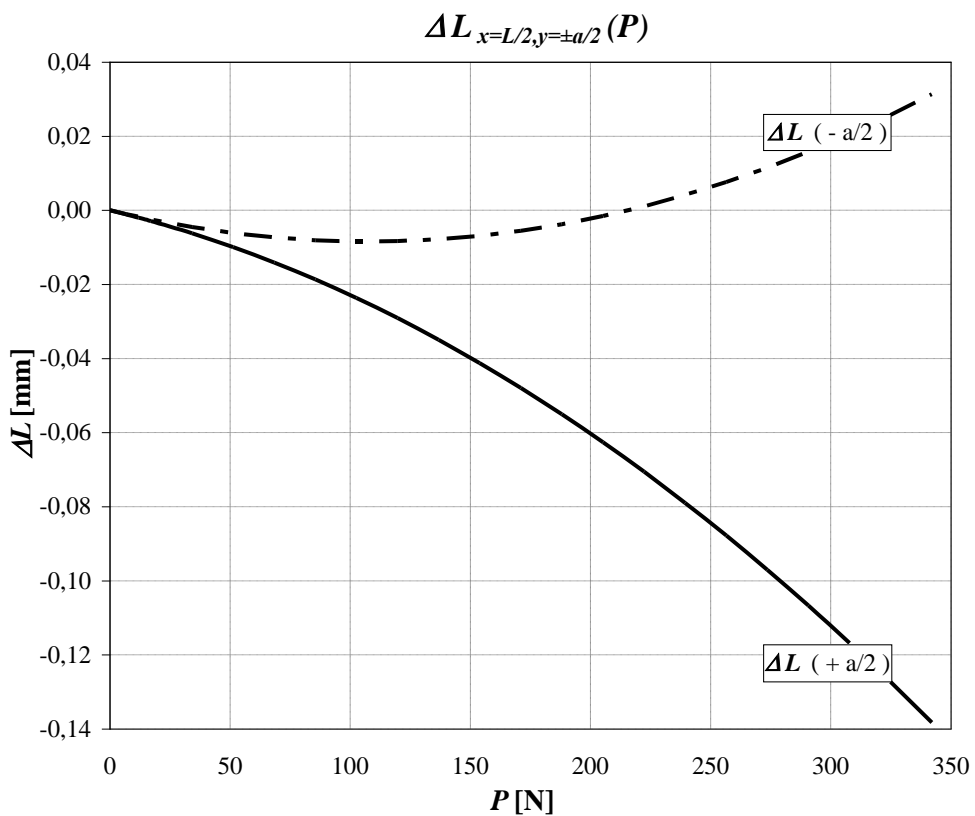

(b)

Fig. 15: Values of (a) coordinate $y_{\sigma=0, x=L}(P)$ of zero normal stress $\sigma_{n}=0$ and (b) deformation $\Delta L_{x=L, y= \pm a / 2}(P)$ in the critical crosssection $(x=L / 2)$, in dependence of $P$ for an axially compressed rectangular shaped shell made of steel (dimensions: $a=20$ $\mathrm{mm}, b=28 \mathrm{~mm}, t=1 \mathrm{~mm}, L=2500 \mathrm{~mm})$.

Because of this reason, it is found that: $\sigma_{c r}{ }^{\text {Euler }}(\lambda)>$ $\sigma_{c r}{ }^{\text {balls }}$ rectangular $(\lambda, A, a / b=0.714, t / b=0.0357)$ for $A<2.6327$ and $\sigma_{c r}^{\text {Euler }}(\lambda)<\sigma_{c r}^{\text {balls }}{ }_{\text {rectangular }}(\lambda, A, a / b=$ $0.714, t / b=0.0357$ ) for $A<2.6327$.

Some conclusions that can be thus drawn from the analysis of the surface function for $\sigma_{c r}{ }^{\text {balls }}$ rectangular $(\mu, \chi, \zeta=$ $28, t=1$ ) that was shown in Fig. $3 \mathrm{~b}$.
With the increase of $\mu$ and the decrease of $\chi$, in particular, it is observed that the stress value $\sigma_{c r}^{\text {balls }}{ }_{\text {rectangular }}(\mu, \chi, \zeta=28, t=1)$ also increases and this is in agreement with the original Euler's formulation, as also shown in Fig. 6b. The graph in Fig. 3c, moreover, shows that with the increase of both the $\zeta$ and $\chi$ parameters, the measured stress value $\sigma_{c r}{ }^{\text {balls }}$ rectangular 
$(\mu, \chi, \zeta=20, t=1)$ decreases at constant values of the ratio $\mu=a / t$ and thickness $t$.

The graph in Fig. 3d, finally, shows that with the increase of the ratio $b / a$ and the increase of the ratio $t / a$, the stress $\sigma_{c r}^{\text {balls }}$ rectangular $(t, \chi, \mu=20, \zeta=28)$ decreases at constant values of the ratio $\chi=L / t$ and the thickness $t$.

Figure $4 \mathrm{~b}$ shows that with the increase of the ratio $b / a$ and with the increase of ratio $t / a$, the stress $\sigma_{c r}{ }^{\text {balls }}{ }_{\text {rectangular }}(b / a, t / a, \lambda=314.8, a=20)$ decreases at constant values of slenderness ratio $\lambda$ and $a$.

From the analysis of the surface function $\sigma_{c r}$ balls_thinwalled $_{\text {rectangular }}(\lambda, A, a / b=0.714)$ shown in Fig. 5a and of the surface function $\sigma_{c r}$ balls_thin-walled $_{\text {rectangular }}(\lambda, A, a / b=0.714)$ that is proposed in Fig. $5 \mathrm{~b}$, it is then possible to observe that - in case of thin walled columns - with the increase of the slenderness ratio $\lambda$ and cross-section area $A$ at constant values of the ratios $a / b$, the measured stress value $\sigma_{c r}$ balls_thin-walled $_{\text {rectangular }}(\lambda, A, a / b=0.714)$ also decreases.

The surface functions $\sigma_{c r}^{\text {Euler's balls }}$ rectangular $=(\mu, \chi, \zeta)$ and $\sigma_{c r}^{\text {Euler's_balls }}$ rectangular $=(a, b, L, t)$, based on Euler's formulation, are not sensitive to the cross-section area $A$.

However, the Euler's formula does not distinguish the obtained results in dependence on the profile of the cross-section for the examined column.

This is indeed something that the technical stability formulation can capture.

On the graph in Fig. 7a, it is possible to see that the limited slenderness ratio $\lambda_{e l-l t}(A, b / a, t / a=0.05)$, with the increase of the $b / a$ ratio, minimally decreases, while strongly decreases at constant values of the ratio $t / a$ with the increase of the cross-section area $A$. On the graph in Fig. $7 \mathrm{~b}$ we see that the limited slenderness ratio $\lambda_{\text {el-lt }}(A$, $t / a, b / a=1.4)$ with the increase of the ratio $t / a$ increases and with the increase of the cross-section areas $A$ decreases strongly at constant values of the ratio $b / a$.
On the graph in Fig. 8 we see that the limited slenderness ratio $\lambda_{\text {el-lt }}^{\text {thin-walled }}(A, t / a, b / a=1.4)$ with the increase of the ratio $a / b$ increases and with the increase of the cross-section area $A$ strongly decreases.

On the graphs in Figs. 9a, 10a, 12a and 13a it is possible to see that the values of the stresses $\sigma_{n}(x, y)$, strains $\varepsilon_{n}(x, y)$ and deformations $\Delta L(x, y)$ for $P=0.1 P_{c r}$ and $0.5 P_{c r}$ in the rectangular shell made of steel with dimensions: $a=20 \mathrm{~mm}, b=28 \mathrm{~mm}, t=1 \mathrm{~mm}, L=2500$ $\mathrm{mm}$ compressed by ball-and-socket joints have minus sign, i.e., all fibers in parallel to the column axis direction are compressed. That means also that all fibers in perpendicular to the direction of the column axis direction are tensioned (Figs. 9b, 10b, 11b and 12b).

From the graphs in Figs. 13a and $14 \mathrm{a}$ it can be noticed that the values of stresses $\sigma_{n}(x, y)$, strains $\varepsilon_{n}(x, y)$ and deformations $\Delta L(x, y)$ in the rectangular shell (for $P$ $\left.=P_{c r}\right)$ have partially negative sign. In this region, the fibers that are parallel to the column axis are compressed, while they are tensioned in the direction perpendicular to the column axis (Figs. 13b and 14b).

In the region where the stress, strain, deformation values have positive sign, the fibers in direction parallel to the column axis are tensioned while they are compressed in the direction perpendicular to the column axis direction (Figs. 13b and 14b).

The phenomena observed during past experimental tests (Murawski and Kłos, 2007) proved that the extensions of the two opposite generating lines are negative at the beginning of the phenomenon of the loss of stability. With the increase of time, however, one of them goes to positive values, as also shown on the graph in Fig. 16. This observation is in line with the technical stability theory (Fig. 15a) and this proves the accuracy of the proposed theory.

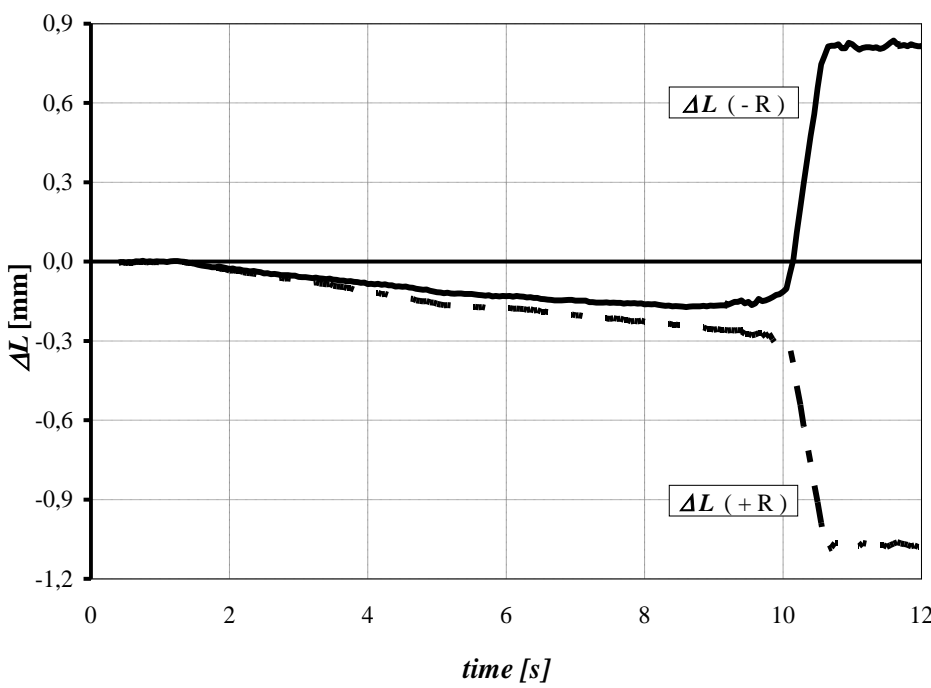

(a)

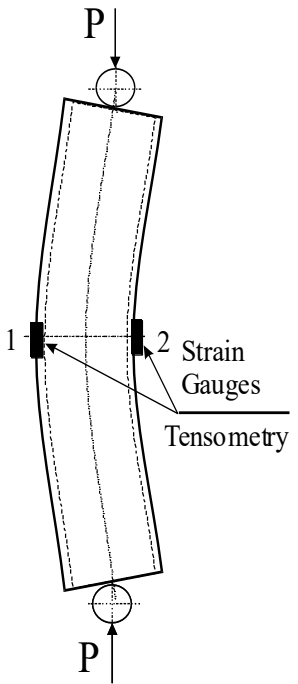

(b)

Fig. 16: (a) Extensions $\Delta L$ in time for a pine column $(870 \times \phi 12 \mathrm{~mm})$, as obtained from (b) the strain gauges placed on the two opposite generating lines (b) in the mid-span cross-section (Murawski and Kłos, 2007). 
The graph in Fig. 15a, finally, shows the coordinate $y_{\sigma_{n}=0, x=L / 2}(P)$ of a zero normal stress $\sigma_{n_{-} x=L / 2}(y)=0$ in the critical cross-section $(x=L / 2)$, in dependence of the imposed load $P$. It is shown that this coordinate is going from infinity to zero, while the load $P$ increases from zero towards $P_{c r}$.

\section{Conclusion}

The design issue of stability for load-bearing members, in general, is a critical step of the overall design process and should be properly addressed. In this study, the attention was focused on the proposition and validation of a theoretical formulation for the technical stability analysis of slender columns in compression. The theoretical study was thus addressed with the support of case-study calculation examples carried out on slender columns made of steel.

\section{Funding}

No funding was received for this research study.

\section{Ethics}

The content of this paper is the changed preprint (Murawski, 2019) according to the issuer requirements and the reviewers and own author's corrections.

\section{Conflicts of Interest}

The author declares no conflict of interest.

\section{References}

Ascione, L., \& Grimaldi, A. (1983). On the stability and postbuckling behaviour of elastic beams. Thinwalled structures, 1(4), 325-351.

Belaid, T., Ammari, F., \& Adman, R. (2018). Influence of load position on critical lateral torsional buckling moment of laterally restrained beam at tense flange. Asian Journal of Civil Engineering, 19(7), 839-848.

Di Sarno, L., \& Manfredi, G. (2012). Experimental tests on full-scale RC unretrofitted frame and retrofitted with buckling-restrained braces. Earthquake Engineering \& Structural Dynamics, 41(2), 315-333.

Euler, L. (1744). De curvis elasticis, Lausanne and Geneva.

Euler, L. (1759). Sur la force des colonnes. Memoires de l'Academie des Sciences de Berlin, 252-282.

Genoese, A., Genoese, A., Rizzi, N. L., \& Salerno, G. (2019). Buckling analysis of single-layer graphene sheets using molecular mechanics. Frontiers in Materials, 6, 26.
Goroshko, A., Royzman, V., Petraschuk, S. (2020). Simulation of a thin long rod that does not have critical forces and does not lose stability to Euler. Problems of Tribology, 25, 3/97-2020, 25-3 I. DOI: $10.31891 / 2079-1372-2020-97-3-25-31$

Gupta, N. K., Sekhon, G. S., \& Gupta, P. K. (2001). A study of lateral collapse of square and rectangular metallic tubes. Thin-walled structures, 39(9), 745-772.

Kalamar, R., Bedon, C., \& Eliášová, M. (2016). Experimental investigation for the structural performance assessment of square hollow glass columns. Engineering Structures, 113, 1-15.

Kiss, L. (2019). Sensitivity of FGM shallow arches to loading imperfection when loaded by a concentrated radial force around the crown. International Journal of Non-Linear Mechanics, 116. DOI: 10.1016/j.ijnonlinmec.2019.05.009

Li, W., Song, Z., \& Chai, Y. (2015). Discrete singular convolution method for dynamic stability analysis of beams under periodic axial forces. Journal of Engineering Mechanics, 141(10), 04015033.

Liang, M., Wu, Z. M., Ueda, T., Zheng, J. J., \& Akogbe, R. (2012). Experiment and modeling on axial behavior of carbon fiber reinforced polymer confined concrete cylinders with different sizes. Journal of Reinforced Plastics and Composites, 31(6), 389-403.

Liu, Y. (2018). Axial and circumferential buckling of a hyperelastic tube under restricted compression. International Journal of Non-Linear Mechanics, 98, $145-153$

Lolov, D., \& Lilkova-Markova, S. (2005). A Plane Problem of the Dynamic Stability of Curved Pipes. Latvian Journal of Physics and Technical Sciences. 6, 24-28.

Malikan, M., Tornabene, F., \& Dimitri, R. (2018). Nonlocal three-dimensional theory of elasticity for buckling behavior of functionally graded porous nanoplates using volume integrals. Materials Research Express, 5(9), 095006.

Marante, M. E., Picon, R. A., Guerrero, N., \& Flã³rezLã ${ }^{3}$ pez, J. U. L. I. O. (2012). Local buckling in three-dimensional frames: Experimentation and simplified analysis. Latin American Journal of Solids and Structures, 9(6), 691-691.

Melissianos, V. E., Lignos, X. A., Bachas, K. K., \& Gantes, C. J. (2017). Experimental investigation of pipes with flexible joints under fault rupture. Journal of Constructional Steel Research, 128, 633-648.

Mohammadi, F. S., Rahimi, Z., Sumelka, W., \& XiaoJun, Y. A. N. G. (2019). Investigation of free vibration and buckling of Timoshenko nano-beam based on a general form of eringen theory using conformable fractional derivative and Galerkin method. Engineering Transactions, 67(3), 347-367. 
Moita, J. S., Araújo, A. L., Correia, V. F., Soares, C. M. M., \& Herskovits, J. (2018). Buckling and nonlinear response of functionally graded plates under thermomechanical loading. Composite Structures, 202, 719-730.

Monsalve-Cano, J. F., \& Aristizábal-Ochoa, J. D. (2016). Stability and free vibration analyses of orthotropic 3d beam-columns with singly symmetric section including shear effects. Engineering Structures, 113, 315-327.

Moradi-Dastjerdi, R., \& Malek-Mohammadi, H. (2017). Free vibration and buckling analyses of functionally graded nanocomposite plates reinforced by carbon nanotube. Mechanics of Adv

Moustabchir, H., Arbaoui, J., El Moussaid, M., Azari, Z., \& Pruncu, C. I. (2018). Characterization of fracture toughness properties of aluminium alloy for pipelines. Experimental Techniques, 42(6), 593-604.

Mozafari, H., Lin, S., Tsui, G. C., \& Gu, L. (2018). Controllable energy absorption of double sided corrugated tubes under axial crushing. Composites Part B: Engineering, 134, 9-17.

Murawski, K. (1992). Stability of thin shell columns in plastic states. 14 Międzynarodowe Sympozjum Naukowe Studentów i Młodych Pracowników Nauki.

Murawski, K. (2011). Theory of Technical Stability of Slender Plywood Rods. Publishing House of Warsaw University of Technology.

Murawski, K. (2018). Technical Stability of Very Slender Thin-walled Orthotropic Columns.

Murawski, K. (2019). Stability, shell stress and strain technical analysis in elastic states of very slender rectangular column compressed by ball-and-socket joints without friction. DOI: 10.13140/RG.2.2.28299.64808

Murawski, K., \& Kłos, R. (2007). Experimental determining of extensions during test of stability of the rode $870 \times 412 \mathrm{~mm}$ made of pine compressed by ball-and-socket joints. Annals of Warsaw University of Life Sciences-SGGW Forestry and Wood Technology, (62), 70-72.

Naderpour, H., Nagai, K., Haji, M., \& Mirrashid, M. (2019). Adaptive neuro-fuzzy inference modelling and sensitivity analysis for capacity estimation of fiber reinforced polymer-strengthened circular reinforced concrete columns. Expert Systems, 36(4), e12410.

Naveed, A., Xue, P., Kamran, M., Zafar, N., Mustafa, A., \& Zahran, M. S. (2017). Investigation of the energy absorption characteristics of metallic tubes with curvy stiffeners under dynamic axial crushing. Latin American Journal of Solids and Structures, 14(7), 1293-1313.
Nguyen, N. D., Nguyen, T. K., Vo, T. P., \& Thai, H. T. (2018). Ritz-based analytical solutions for bending, buckling and vibration behavior of laminated composite beams. International Journal of Structural Stability and Dynamics, 18(11), 1850130.

Nouri, M. D., Hatami, H., \& Jahromi, A. G. (2015). Experimental and numerical investigation of expanded metal tube absorber under axial impact loading. Structural Engineering and Mechanics, 54(6), 1245-1266.

Oleiwi, J. K., Al-Hassani, E. S., \& Abd Mohammed, A. (2014). Modeling and Buckling Analysis of Polymeric Composite Columns. Engineering and Technology Journal, 32(5 Part (A) Engineering), 1180-1196.

Osmani, A., \& Meftah, S. A. (2018). Lateral buckling of tapered thin walled bi-symmetric beams under combined axial and bending loads with shear deformations allowed. Engineering Structures, 165, 76-87.

Özbasaran, H., Aydin, R., \& Dogan, M. (2015). An alternative design procedure for lateral-torsional buckling of cantilever I-beams. Thin-Walled Structures, 90, 235-242.

Psyrras, N., Kwon, O., Gerasimidis, S., \& Sextos, A. (2019). Can a buried gas pipeline experience local buckling during earthquake ground shaking?. Soil Dynamics and Earthquake Engineering, 116, 511-529.

Qi, Y., Xie, L., Bai, Y., Liu, W., \& Fang, H. (2019). Axial compression behaviours of pultruded GFRPwood composite columns. Sensors, 19(4), 755.

Rahmani, O., Refaeinejad, V., \& Hosseini, S. A. H. (2017). Assessment of various nonlocal higher order theories for the bending and buckling behavior of functionally graded nanobeams. Steel Compos. Struct, 23(3), 339-350.

Rahnavard, R., Naghavi, M., Aboudi, M., \& Suleiman, M. (2018). Investigating modeling approaches of buckling-restrained braces under cyclic loads. Case studies in construction materials, 8, 476-488.

Rao, L. B., \& Ra, C. K. (2009). Buckling of circular plates with a ring support and elastically restrained edge. Advances in Vibration Engineering, 8(1), 59-67.

Riahi, F., Zirakian, T., Ghaderi, V. M., \& Arya, S. (2018). Buckling stability assessment of plates under uniaxial compression. Advances in Science and Technology Research Journal, 12.

Sabouri-Ghomi, S., Kharrazi, M. H., Mam-Azizi, S. E. D., \& Sajadi, R. A. (2008). Buckling behavior improvement of steel plate shear wall systems. The Structural Design of Tall and Special Buildings, 17(4), 823-837. 
Sadath, A., Vinu, V., \& Vyasarayani, C. P. (2017). Vibrations of a simply supported cross flow heat exchanger tube with axial load and loose supports. Journal of Computational and Nonlinear Dynamics, 12(5).

Schnabl, S., Planinc, I., \& Turk, G. (2013). Buckling loads of two-layer composite columns with interlayer slip and stochastic material properties. Journal of Engineering Mechanics, 139(8), 961-966.

Singh, S. J., \& Harsha, S. P. (2019). Buckling analysis of FGM plates under uniform, linear and non-linear inplane loading. Journal of Mechanical Science and Technology, 33(4), 1761-1767.

Slimani, A., Ammari, F., \& Adman, R. (2018). The effective length factor of columns in unsymmetrical frames asymmetrically loaded. Asian Journal of Civil Engineering, 19(4), 487-499.

Sun, G., Li, S., Li, G., \& Li, Q. (2018). On crashing behaviors of aluminium/CFRP tubes subjected to axial and oblique loading: an experimental study. Composites Part B: Engineering, 145, 47-56.

Thermou, G. E., Katakalos, K., \& Manos, G. (2018). Experimental investigation of substandard RC columns confined with SRG jackets under compression. Composite Structures, 184, 56-65.
Vu, Q. V., Papazafeiropoulos, G., Graciano, C., \& Kim, S. E. (2019). Optimum linear buckling analysis of longitudinally multi-stiffened steel plates subjected to combined bending and shear. Thin-Walled Structures, 136, 235-245.

Wang, J., Shen, Q., Jiang, H., \& Pan, X. (2018). Analysis and design of elliptical concrete-filled thin-walled steel stub columns under axial compression. International journal of steel structures, 18(2), 365-380.

Wahrhaftig, A. M., Brasil, R. M. L. R. F., \& César S. F. (2016). Creep in the fundamental frequency and stability of a slender wooden column of composite section. DOI: 10.1590/0100-67622016000600018

Xu, D., Zhao, Z., \& Zhou, J. (2013). Design and Characteristic Analysis of a Buckling Plate Vibration Isolator with Quasi zero-stiffness. Journal of Hunan University (Natural Sciences), 40(6), 47-52.

Ye, J., Mojtabaei, S. M., \& Hajirasouliha, I. (2018). Local-flexural interactive buckling of standard and optimised cold-formed steel columns. Journal of constructional steel research, 144, 106-118.

Zhou, T., Lu, Y., Li, W., \& Wu, H. (2017). End condition effect on distortional buckling of coldformed steel columns with arbitrary length. ThinWalled Structures, 117, 282-293. 